\title{
Social and Economic Value in Emerging Decentralized Energy Business Models: A Critical Review
}

\author{
Sophie Adams ${ }^{1, *(\mathbb{D}}$, Donal Brown ${ }^{2}$, Juan Pablo Cárdenas Álvarez ${ }^{3} \mathbb{C}^{\circ}$, Ruzanna Chitchyan ${ }^{4} \mathbb{D}$, Michael J. Fell ${ }^{5}$, \\ Ulf J. J. Hahnel ${ }^{6}{ }^{\circledR}$, Kristina Hojckova ${ }^{7}$, Charlotte Johnson ${ }^{5}$, Lurian Klein ${ }^{8}{ }^{\circledR}$, Mehdi Montakhabi ${ }^{9}{ }^{\circledR}$, \\ Kelvin Say ${ }^{10}\left(\mathbb{D}\right.$, Abhigyan Singh ${ }^{11}$ (i) and Nicole Watson ${ }^{5}$
}

check for

updates

Citation: Adams, S.; Brown, D.; Cárdenas Álvarez, J.P.; Chitchyan, R.; Fell, M.J.; Hahnel, U.J.J.; Hojckova, K.; Johnson, C.; Klein, L.; Montakhabi, M.; et al. Social and Economic Value in Emerging Decentralized Energy Business Models: A Critical Review. Energies 2021, 14, 7864. https:// doi.org/10.3390/en14237864

Academic Editor: Beata Zofia Filipiak

Received: 26 October 2021

Accepted: 16 November 2021

Published: 24 November 2021

Publisher's Note: MDPI stays neutral with regard to jurisdictional claims in published maps and institutional affiliations.

Copyright: (c) 2021 by the authors. Licensee MDPI, Basel, Switzerland. This article is an open access article distributed under the terms and conditions of the Creative Commons Attribution (CC BY) license (https:// creativecommons.org/licenses/by/ $4.0 /)$.
School of Humanities and Languages, University of New South Wales, Kensington, NSW 2052, Australia

2 Science Policy Research Unit (SPRU), University of Sussex, Brighton BN1 9RH, UK; donal.brown@sussex.ac.uk

3 EnergEIA, Universidad EIA, Envigado 055428, Colombia; juan.cardenas33@eia.edu.co

4 Department of Computer Science, University of Bristol, Bristol BS8 1TH, UK; r.chitchyan@bristol.ac.uk

5 Energy Institute, University College London, London WC1E 6BT, UK; michael.fell@ucl.ac.uk (M.J.F.); c.johnson@ucl.ac.uk (C.J.); nicole.watson.17@ucl.ac.uk (N.W.)

6 Department of Psychology and Swiss Center for Affective Sciences, University of Geneva, 1205 Geneva, Switzerland; ulf.hahnel@unige.ch

7 Department of Technology Management and Economics, Chalmers University of Technology, 41296 Göteborg, Sweden; kristinahojckova@gmail.com

8 Sustainable Energy Systems Doctoral Programme, MIT Portugal Initiative, University of Coimbra, 3004-531 Coimbra, Portugal; lurianklein@hotmail.com

9 imec-SMIT, Vrije Universiteit Brussel, 1050 Ixelles, Belgium; mehdi.montakhabi@vub.be

10 Energy Transition Hub, University of Melbourne, Parkville, VIC 3010, Australia; kelvin.say@unimelb.edu.au

11 Faculty of Industrial Design Engineering, Delft University of Technology (TU Delft), 2628 CD Delft, The Netherlands; abhigyan.singh@gmail.com

* Correspondence: s.m.adams@unsw.edu.au; Tel.: +61-02-9348-0562

Abstract: In recent years, numerous studies have explored the opportunities and challenges for emerging decentralized energy systems and business models. However, few studies have focussed specifically on the economic and social value associated with three emerging models: peer-to-peer energy trading (P2P), community self-consumption (CSC) and transactive energy (TE). This article presents the findings of a systematic literature review to address this gap. The paper makes two main contributions to the literature. Firstly, it offers a synthesis of research on the social and economic value of P2P, CSC and TE systems, concluding that there is evidence for a variety of sources of social value (including energy independence, local benefits, social relationships, environmental responsibility and participation and purpose) and economic value (including via self-consumption of renewable electricity, reduced electricity import costs, and improved electricity export prices). Secondly, it identifies factors and conditions necessary for the success of these models, which include willingness to participate, participant engagement with technology, and project engagement of households and communities, among other factors. Finally, it discusses conflicts and trade-offs in the value propositions of the models, how the three models differ from one another in terms of the value they aim to deliver and some of the open challenges that require further attention by researchers and practitioners.

Keywords: social value; economic value; peer-to-peer electricity trading; community self-consumption; transactive energy; energy business models

\section{Introduction}

In recent years, numerous studies have explored the opportunities and challenges for emerging decentralized energy systems and business models. These include review papers which discuss the potential contribution to low carbon energy system from decentralized photovoltaics [1], electricity storage [2], smart grids [3] and microgrids [4]. Other review 
studies have focused on emerging business models [5], including business models for demand side management [6], peer-to-peer (P2P) trading [7], transactive energy (TE) markets [8] and microgrids which involve community self-consumption (CSC) [9]. However, few studies have focussed specifically on the social and economic value that the P2P, TE, and CSC business models create.

In this paper we address this gap. Our aim is to identify the forms of social and economic value that are attributed to P2P, CSC, and TE models in theory or in practice by the existing literature, and the factors that explain the extent to which these forms of value are realized. For example, these models are widely seen to hold the promise of economic benefits for their participants in the form of reduced energy costs or income, as well as independence, empowerment and strengthened relationships for local communities. This paper examines the evidence to support such expectations and to attempts explain where and why these models are being embraced by participants. As well as offering prosumers a more active role in electricity markets, these three models hold different potential for value generation, and may, therefore, be taken up differently according to energy users preferences [10]. While these models are emerging in the context of efforts to decarbonize energy systems around the world, this paper does not assess the environmental value that may be derived from these models. It considers environmental value only where such a value is related to social and economic values that motivate participation in these models.

As this is an evolving and highly multidisciplinary field, a universally accepted definition of P2P, CSC, and TE models is lacking. A systematic review of definitions from Watson and Gorbatcheva [11] found that all three models are characterized by small scale participants, typically users with solar PV, trading or sharing energy directly with one another. There are, however, distinctions between the aims, scale, operation, and governance of each of the models [11]. P2P places greater emphasis on direct transactions between individuals without an intermediary, with competitive markets that can be either bound to a local community or encompass virtual trading across a large geographical region. P2P can include participants that are heterogeneous in type but are typically similar in scale. Incentives for participating in P2P markets can be individualistic, such as economic benefits, or pertain to social or environmental outcomes. Transactive energy focuses more on outcomes pertaining to system benefits, such as integration of distributed energy resources (DER) or balancing demand and supply through aggregation of participant loads. Transactive energy can operate across various levels of the electricity grid and scales, encompassing diverse participants. By contrast, CSC is characterized by a smaller scale, often bound to a specific local area. CSC often features shared ownership of generation assets, with the community itself acting as a legal entity for market participation. Out of the three models, CSC places the most focus on community benefits and sharing those benefits across the community.

As a group of researchers engaged in a sub-task dedicated to social and economic value within the Global Observatory on Peer-to-Peer Energy Trading, Community SelfConsumption and Transactive Energy (GO-P2P), we conducted a systematic literature review of this field. We identified 36 directly relevant articles that offered empirical findings. The analysis of these articles was guided by the overarching question: What are the key social and economic factors constraining or shaping the design, uptake, and impacts of P2P, CSC, and TE models? Because of the relatively early stage of development of this field, only limited real-world trials have yet been conducted. These are complemented by work based around surveys and interviews which sets out to explore expectations rather than experience of P2P, CSC, and TE models. A key part of the value of this synthesis is in setting up an agenda for how research and development in this space can move forward in a way that is sensitive to different kinds, and different beneficiaries, of social and economic value.

The paper is organized as follows. Section 2 introduces the concepts of social value and economic value. Section 3 provides details on the systematic literature review methodology. Sections 4 and 5 set out the results of the analysis: Section 4 examines the forms of social and economic value associated with P2P, CSC and TE models and Section 5 examines the 
factors and conditions of model uptake and success that are evidenced in the literature reviewed. Section 6 discusses these findings, and Section 7 concludes the paper with some recommendations for researchers and practitioners.

\section{Background Concepts}

\subsection{Social Value}

The study of human values, or 'what is important to us in life' [12] (p. 3), has long been a research topic in social sciences and humanities. Researchers have explored how, while, on the one hand some human values appear to be universally held, on the other hand, they are also extremely subjective and context-sensitive. Each individual and group holds their own subjective subset of these values which vary in importance [12].

Thus, social values are inherently normative, and may be contested by different groups and at different points in space and time. Brown et al. [13] reflect on these 'competing normativities' in their paper on the emerging renewable energy prosumer landscape. The paper highlights how market, state and community actors may adopt very different 'value logics' [14] when evaluating the future benefits of decentralised energy systems. For example, market actors may emphasize the efficiency gains from prosumer models which enable users to maximize their utility through price signals [15]. Contrastingly, community actors may instead emphasize the social bonds and direct democracy enabled by energy cooperatives [16], while state actors may foreground their potential to deliver social policy objectives such as reduced inequality and social exclusion [17]. Clearly then, the purported social value created by P2P, CSC and TE models is likely to be heavily shaped by the cultural, economic and institutional context from which the model emerges, as well as the power structures, political struggles and actor relationships within these contexts [18]. Discussion of the social value of P2P, CSC and TE models must therefore be cognizant of these dynamics, and the divergent outcomes they might produce.

In terms of detailed study of the social values ascribed to P2P energy sharing models, Klein et al. [19] devised a social values-based assessment framework which includes 194 individual social values that can be explicitly associated with P2P energy sharing interactions, which are categorized under 33 macro themes (e.g., belonging, achievement, responsibility, resilience, altruism, influence, emancipation, awareness, participation, etc.) for operationalization purposes. The framework (validated with three Portuguese pilot studies) allowed participants to make inferences about the nature of each active social value. This paper explores only those values that are discussed in the research papers identified as relevant to the present study.

\subsection{Economic Value}

The emergence of P2P, CSC and TE business models is also driven by their potential to increase the economic value, or the amount of money, goods or services, that may be derived from decentralized energy systems. Indeed, the disruptive potential of decentralized energy systems for the prevailing utility business model is well documented in the literature $[5,20,21]$. It is argued that the characteristics of decentralized energy systems necessitate alternative 'prosumer business models', enabling the self-consumption of renewable electricity, the trading of surplus power and rewarding participants for the provision of flexibility to the electricity networks and system operators [22]. Brown et al. [23] argue that these business models can create economic value in four main ways: (1) increase self-consumption behind the meter; (2) achieve improved prices for exported power; (3) access wholesale, balancing and ancillary service markets; and (4) shift energy vectors to heat and transportation, sometimes referred to as 'sector coupling' [24]. In addition, other authors have highlighted how these business models may also drive local economic value in the form of community wealth, job creation and new revenue streams [25]. However, tensions also begin to emerge as these new P2P, CSC and TE business models require cooperation from utility stakeholders, such as retailers and distribution network owners. While this review focuses on the socio-economic values of participating consumers and 
prosumers, it also considers the importance of finding synergies from decentralized energy systems in order to balance the competing value streams between users and utilities.

\section{Method}

We used a systematic review approach to answer the review questions set out in Section 1 . This section describes the process by which we identified and selected documents to include in the review, and how we extracted and synthesized information. We adhere to the PRISMA guidelines [26] for reporting systematic reviews as far as possible.

\subsection{Search}

We sought to identify all English-language empirical evidence or conceptual/theoretical consideration of social and economic value connected with P2P, CSC and TE. We restricted our enquiry to peer-reviewed academic literature. This has a level of built-in quality assurance through peer review, is more convenient (as literature databases can be used), and potentially brings greater impartiality compared to commercial reports. However, it does mean that relevant projects reported in the grey literature may have been missed. Our exclusion of documents in languages other than English also means that we may have missed valuable evidence available from some parts of the world.

We conducted searches on the databases Scopus, Web of Science and ScienceDirect. Searches were developed to capture the concepts of P2P, CSC and TE, social/economic factors, and energy/electricity. These were piloted in various combinations with the aim to 'identify the best available evidence to address a particular question without producing an unmanageable volume of results' [27]. The concepts, operationalized search terms and the final search string we used are shown in Table 1.

Searches were run in August 2020, and details are shown in Appendix A. Bibliographic details of all search results were downloaded into the reference management software Zotero.

Table 1. The concepts and search terms used in the review, along with an example search string used in the database Scopus.

\begin{tabular}{lll}
\hline \multicolumn{1}{c}{ P2P/CSC/TE } & \multicolumn{1}{c}{ Social/Economic Value } \\
\hline & & Prosumers/consumers/customers/users \\
& & Community \\
Independence & Sufficiency \\
& & Democracy \\
& & Rights \\
Peer-to-peer & Justice \\
Transactive & Value \\
Community self-consumption & Equity/equality \\
Local/decentralised/distributed & Energy & Markets \\
energy trading & Electricity & Economic \\
Energy exchange & Power & Financial \\
Private wire & & Bills/pricing/costs \\
& Minigrid & Income/earnings/returns \\
& & Bills/pricing/costs \\
& & Income/earnings/returns \\
& & Business \\
& & Poverty \\
& & Culture \\
& & Commons \\
\end{tabular}


Table 1. Cont.

\begin{tabular}{|c|c|c|c|}
\hline & P2P/CSC/TE & Energy & Social/Economic Value \\
\hline 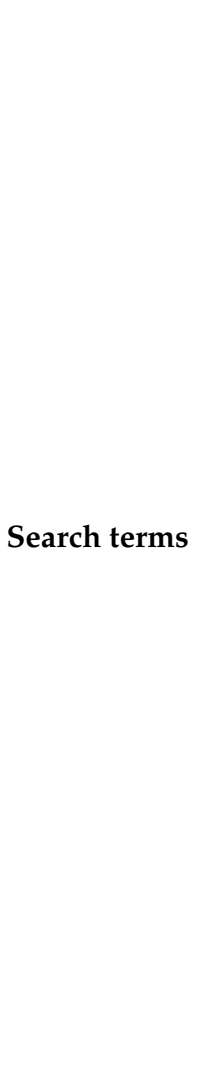 & $\begin{array}{l} \\
\text { peer-to-peer } \\
\text { "peer to peer" } \\
\text { p2p } \\
\text { "commun* self-consump*" } \\
\text { "local energy market" } \\
\text { "mutual energy exchange" } \\
\text { "local energy trading" } \\
\text { "decentralised energy trading" } \\
\text { "distributed energy trading" } \\
\text { "private wire" } \\
\text { minigrid* }\end{array}$ & $\begin{array}{l}\text { energy } \\
\text { electricity } \\
\text { power }\end{array}$ & $\begin{array}{l}\text { societ* } \\
\text { social } \\
\text { prosumer* } \\
\text { consumer* } \\
\text { customer } \\
\text { user } \\
\text { communit* } \\
\text { independen* } \\
\text { *sufficien* } \\
\text { democra* } \\
\text { right* } \\
\text { justice } \\
\text { *equit* } \\
\text { *equal* } \\
\text { "non-market" } \\
\text { value } \\
\text { econom* } \\
\text { financ* } \\
\text { bill* }^{*} \\
\text { pric* } \\
\text { cost* } \\
\text { income } \\
\text { business } \\
\text { earn* } \\
\text { pover* } \\
\text { cultur* } \\
\text { common* } \\
\text { return* }\end{array}$ \\
\hline
\end{tabular}

TITLE-ABS-KEY ("peer-to-peer" OR "peer to peer" OR p2p OR “commun* self-consump*" OR transactive OR "local energy market*" OR "mutual energy exchange" OR "local energy trading" OR "decentralised energy trading" OR "distributed energy trading" OR "private wire" OR minigrid*) AND TITLE-ABS-KEY (energy OR electricity OR power) AND TITLE-ABS-KEY (societ* OR social OR prosumer* OR consumer* OR customer OR user OR communit* OR independen* OR *sufficien* OR democra* OR right* OR justice OR *equit* OR *equal* OR "non-market" OR econom* OR financ* OR bill* OR pric* OR cost* OR income OR business OR earn* OR pover* OR cultur ${ }^{*}$ OR common* OR return*)

(Note: Here * is used in a search string to capture words with the same root but alternative prefixes or suffixes; e.g., societ* will match such words as society, societal, etc.).

\subsection{Screening}

Documents were divided up amongst the authors and a number of other members of the GO-P2P sub-task and screened on the basis of title and abstract against the eligibility criteria presented in Table 2.

Following initial screening, the wider GO-P2P sub-task membership was invited to read through the shortlist and suggest additional articles that the search process may have missed. Seeking such expert input is recommended when it is considered challenging to rely on database searches in a way that 'balances recall and precision' [27], as is commonly the case when the topic of the review is broad. Any documents contributed at this stage were also passed through the screening process. All documents that passed initial screening were further screened by looking at the full text of the article. The process by which we arrived at the final sample of records, and the number of records at each stage, are shown in Figure 1. The final sample of records included in the literature review are references $[13,19,23,28-60]$. 
Table 2. Inclusion and exclusion criteria.

\begin{tabular}{c}
\hline Inclusion Criteria \\
English language \\
\hline $\begin{array}{l}\text { Contains empirical or conceptual/theoretical consideration of } \\
\text { economic and social value produced by } \mathrm{P} 2 \mathrm{P} / \mathrm{CSC} / \mathrm{TE} \text { models. }\end{array}$
\end{tabular}

\section{Exclusion Criteria}

Non-English language

economic and social value produced by P2P/CSC/TE models.

Sources considering only the broad factors driving/impeding these models if they make no reference to social and economic factors/values.

Involves some engagement with participants of actual pilots or trials, or hypothetical P2P/CSC/TE models

Sources based only on modelling analysis (i.e., based on assumptions about potential value), rather than any empirical engagement

Sources that consider economic value but in ways unrelated to economic value for the participants of P2P/CSC/TE models and their local communities (e.g., sources focused exclusively on value for actors other than the local community.

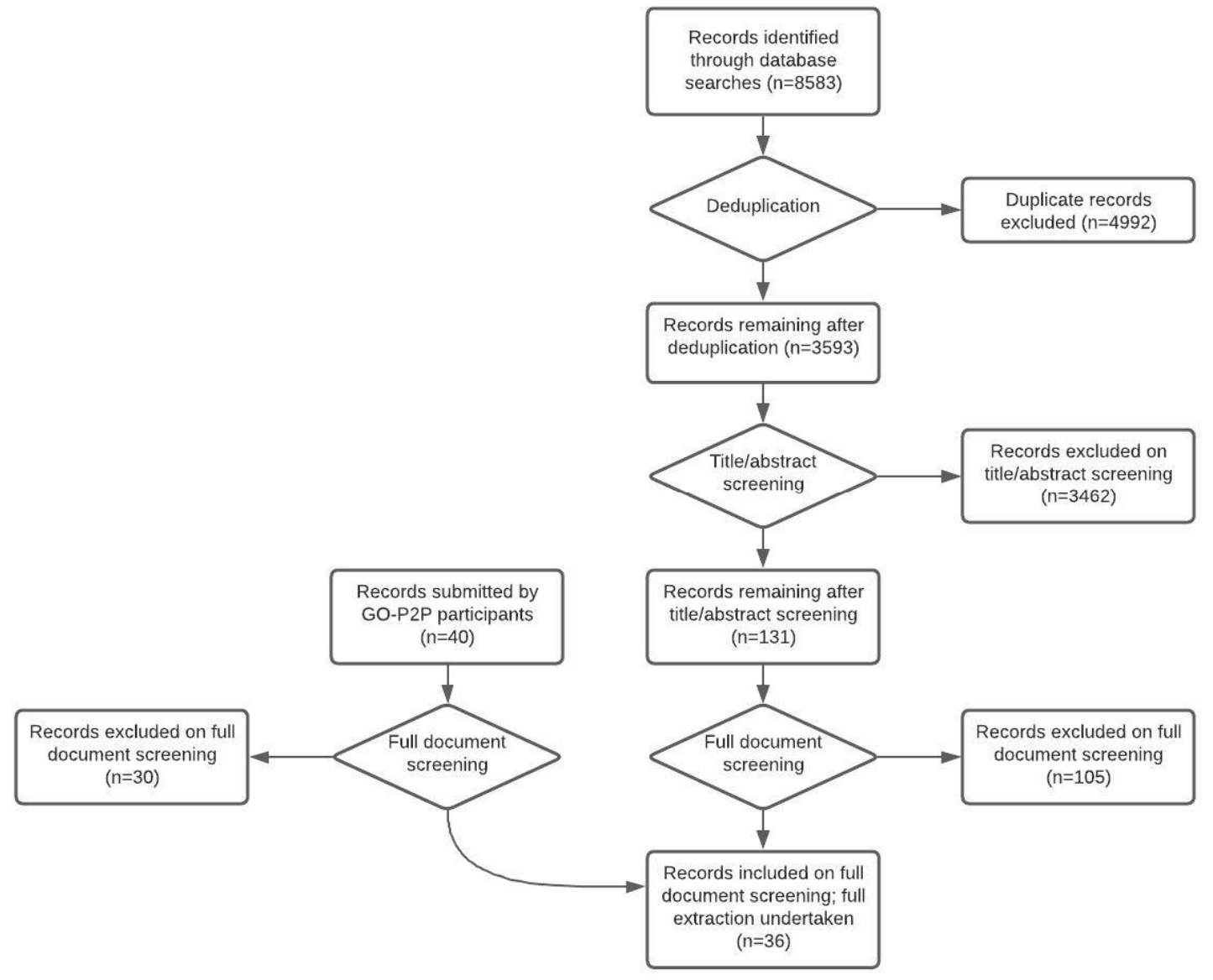

Figure 1. Flowchart showing the review process.

\subsection{Extraction}

Once a final list of included documents had been established, bibliographic details for each were added to an Excel spreadsheet. Members of the GO-P2P sub-task were each assigned a number of articles from which to extract information. Details of this extraction were recorded in the spreadsheet columns, and were as follows:

1. Type of publication (journal article, book, book chapter, report, conference paper, working paper, etc.) and method

2. Aim and research questions

3. Abstract

4. Relevance (rating or comment) 
5. Facilitating factors: What are the factors, both internal and external, driving or facilitating the design and uptake of P2P/CSC/TE models and the realization of their economic and social value?

6. Impeding factors: What are the factors, both internal and contextual, impeding the design and uptake of P2P/CSC/TE models and the realization of their economic and social value?

7. Economic value: What are the forms of economic value perceived to be offered and/or demonstrated by P2P/CSC/TE models? According to whom? How is this shown?

8. Social value: What are the forms of social value perceived to be offered and/or demonstrated by P2P/CSC/TE models? According to whom? How is this shown?

9. Stakeholder involvement: How do forms of stakeholder involvement shape the design, uptake and impacts of P2P/CSC/TE models?

Since a large range of study types were included, a thematic narrative synthesis approach was taken. Findings were allocated codes, which in turn were collected under the themes discussed in Sections 4 and 5 below. Notes made during the initial extraction process were supplemented by revisiting the original publications, to check for accuracy and to add detail relevant to the themes identified.

It is important to highlight a number of limitations of the review approach we took. While we set out to be as comprehensive as possible in our search of the academic literature, resource constraints, the breadth of the potential subject matter, and rapidly evolving nature of this field mean that we cannot be certain that we have captured all relevant studies. We were able to mitigate the risk of this somewhat by inviting suggestions for documents to include from wider members of the GO-P2P sub-task. Our decision to exclude grey literature also means that consideration of social and economic value reported there will not have been captured. We also did not conduct any quality or risk of bias assessment during the review process. Because one of our primary aims was to identify the range of sources of social and economic value yielded by P2P, CSC and TE models, rather than quantitatively assessing the extent to which any value was delivered, the impact of this is likely to be limited. However, it does limit what we are able to say about the strength of evidence for the potential (or otherwise) of different forms of value to be realized.

\section{The Social and Economic Value Produced by P2P, CSC and TE Models}

The articles identified in the systematic search feature research conducted in a number of regions of the world, as shown in Figure 2. The majority of the studies are about P2P, with smaller proportions concerned with CSC, TE or all three (Figure 3a). Slightly less than half examined a real-world pilot or trial, and slightly more than half examined participants' engagement with a hypothetical model (Figure 3b). While there is longstanding attention to the potential for differences between stated and revealed preferences, we consider both alongside each other in this paper, pointing out the approach and its implications where relevant. Both have strengths and weaknesses, for example related to sample size, recruitment bias, and ecological validity. The studies also drew on a range of academic disciplines (Figure 4).

\subsection{Social Value of P2P, CSC and TE Models}

\subsubsection{Energy Independence}

Energy independence is a central value ascribed to P2P, CSC and TE models by their participants. Two senses of this term are distinguished in the literature: the first being autarky (self-sufficiency or independence of energy supply) and the second autonomy. This is a distinction between the goal, i.e., energy independence, and how it is achieved, i.e., the capacity to self-determine one's own energy provision, according to Ecker, Spada and Hahnel [28], who found in a choice experiment that both senses motivate purchase of household energy storage systems. Smale and Kloppenburg [29] argue that it is necessary to distinguish between the two given that autarky is incommensurable with grid integration, but a participant's desire for autonomy would not preclude willingness to participate in 
grid balancing services for financial returns, for example-provided that they can 'set the terms and conditions' (p. 13). In the workshops they conducted about various 'energy platform' models, the participants valued both, but some recognised that 'solely pursuing self-sufficiency ... would likely introduce "inefficiencies"' (p. 10). As Hahnel et al., point out, autarky challenges P2P trading as 'excessive storing of electricity may reduce the market volume and associated profits' [30].

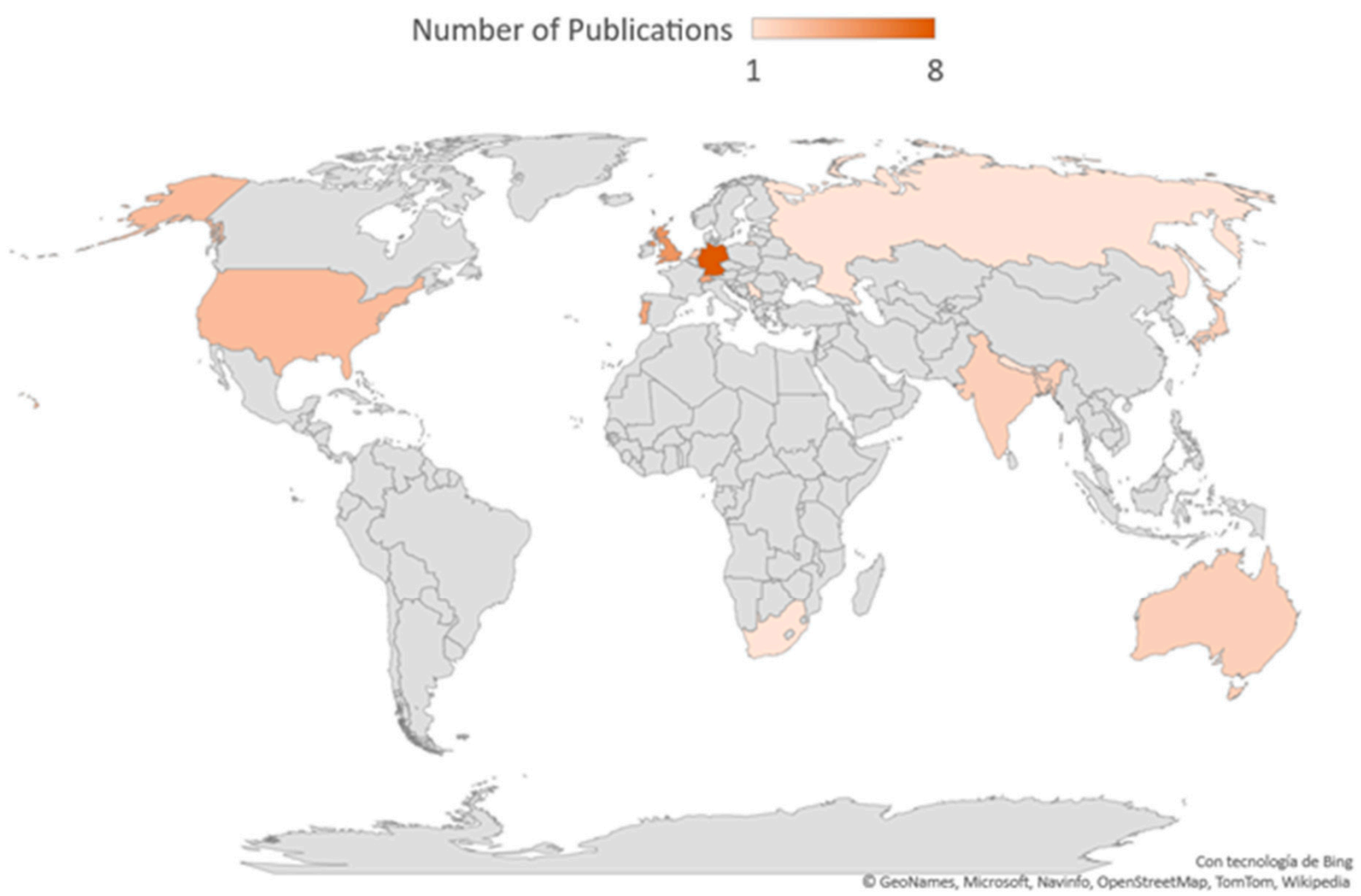

Figure 2. Geographical distribution of current research studies.

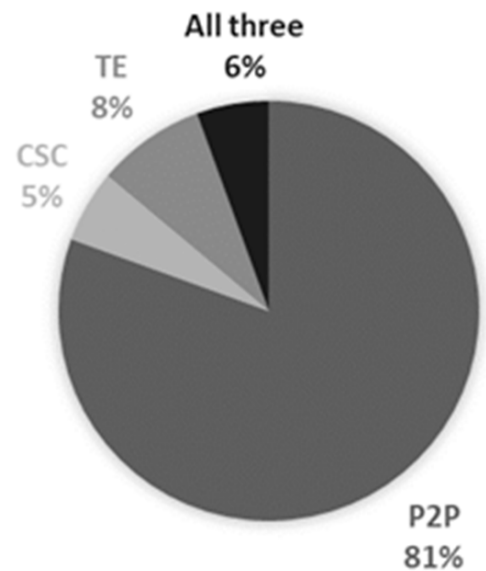

(a)

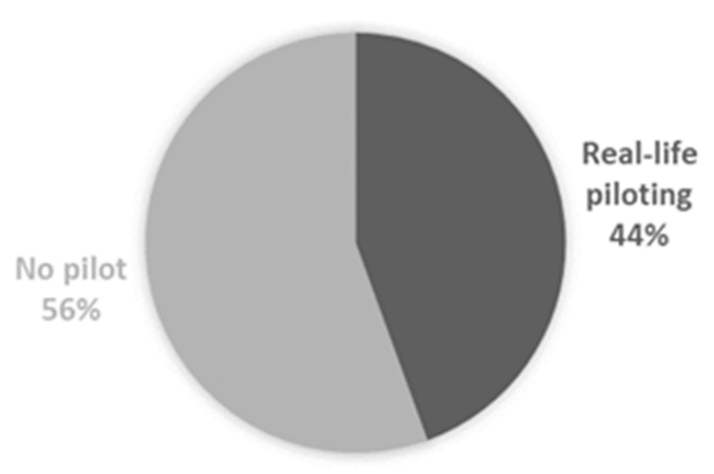

(b)

Figure 3. (a) Proportion of articles about P2P, CSC, TE or all the models; (b) proportion of articles involving real-world piloting. 


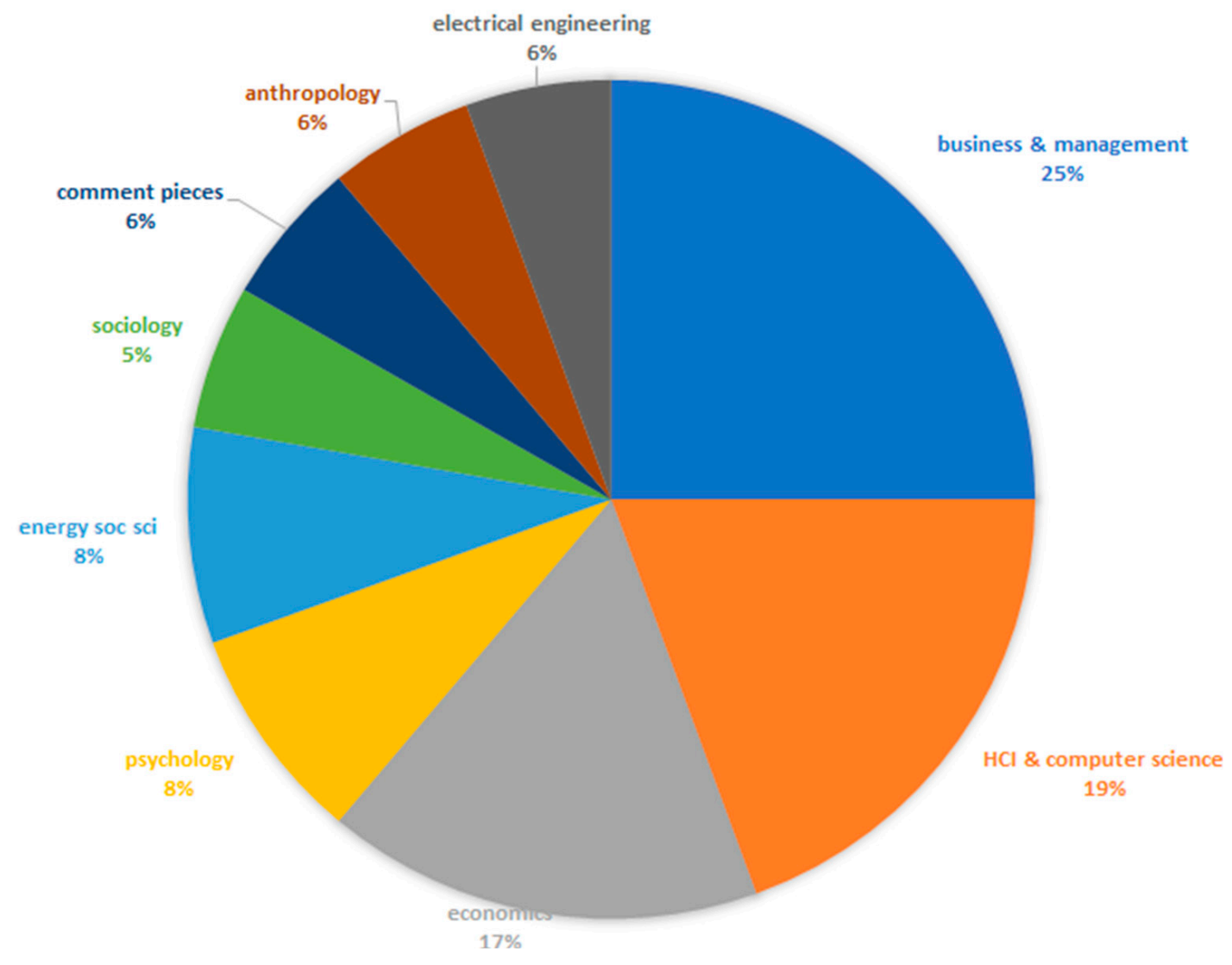

Figure 4. The main discipline of reviewed studies.

Autarky was found to be highly valued in experimental survey studies testing German participants' responses on P2P energy trading scenarios [28,30]. P2P is seen to introduce a tension between meeting households' own needs and sharing excess energy, and some participants have expressed concerns about others draining their battery [31]. Indeed, in their experimental study, Ecker, Spada and Hahnel [28] found that a focus on autarky benefits increases the 'endowment effect', making people assign higher relative value to their own energy and therefore less inclined to trade it. In an experimental study, $31.6 \%$ of participants made trading decisions based more on battery state of charge and were relatively insensitive to price changes [30]. In the Quartierstrom trial in Switzerland, the self-sufficiency rate (SSR), or the proportion of energy demand met by the prosumers consuming their own energy, increased with P2P trading to $16.3 \%$, compared to $15.5 \%$ in a scenario without trading [32]. Increased autarky was also achieved in a demonstration in Japan, a bidding strategy based on the current price of the electricity stored in the battery of each standalone system allowed those with medium or low consumption levels to be self-sufficient by making better use of their self-generated energy [33].

Supporting the value ascribed to autonomy, other studies have found that household interview participants view decarbonization as a way for individuals and communities to take ownership of sustainability. One UK interviewee quoted by Wilkins, Chitchyan and Levine commented that 'wouldn't it be better if communities were independently powered and looked after their own power sources' [34] (p. 6). A desire for autonomy in the sense of independence from an energy provider [35] or codetermination in the energy community [36] can increase willingness to participate among survey participants. Focus groups conducted in the course of establishing the Quartierstrom trial revealed that participants wanted the ability to set their own prices for trades in the local market [37]. In a German country-wide survey, people were willing to pay a slightly higher price if they could have more frequent interaction with the local energy market, i.e., more control [38]. Autonomy was also identified as an 'active' social value in the context of a Portuguese P2P 
energy sharing demonstration project, and perceived by users as a social value that was reinforced by the P2P energy sharing activities [19].

A high level of importance ascribed by households to having detailed information about the origin and production of goods in general correlates with openness to participate in P2P trading [35]-which seems to imply that the sense of oversight and decisionmaking power afforded by such information is valued. Some participants in an Australian P2P trading trial stated that 'they expected it would reduce the need for involvement of the existing retailer' [39] (p. 9). Interestingly, a comparison of the efficiency of the trading in the Quartierstrom trial with modelling of a scenario without trading revealed that the SSR would have been higher if participants' price bids had not been taken into account, suggesting that 'the freedom of decision-making granted to the participants by actively including them in the pricing process thus comes at a trade-off of this decrease in SSR' [32] (p. 10).

The value of autonomy is also related to the extent to which participants wish to actively engage in P2P, CSC and TE models or to rely on automated energy exchange, as is discussed in the 'User characteristics and preferences' section below. Against the value of both senses of energy independence, a choice experiment shows that prosumers were generally willing to accept a certain level of 'inconvenience' in terms of loss of control of battery and reduced self-consumption in exchange for value created through greener or cheaper tariffs [40].

\subsubsection{Local Benefits and Provenance}

The association of P2P, CSC and TE models with a local community or region is another key theme in the literature. Some studies have found that respondents perceive that these models would benefit local communities or regions, in particular demonstrating the viability of a more socially equitable as well as clean energy system [39]; others do not [29].

The expectation of community benefit can make them attractive to some prospective participants [41]. This may be particularly so for study respondents who have a more positive attitude to regionality [35] and sense of community identity [42], while no statistically significant influence was found for the importance of regional products for willingness to participate in local energy markets [42]. The majority of German respondents surveyed by Löbbe et al. [35] indicated a preference for energy communities that are local or regional.

The importance of regionality to prospective participants is likely to differ between places, as Mengelkamp et al. [38] show in their comparison of survey datasets from a German national sample and from the Allgäu region, with regionality more important to the Allgäu residents. Prior to their participation in the Quartierstrom trial in Switzerland, 17 of 31 survey respondents said that they would be willing to pay a premium for local energy [32], while four of the nine households interviewed following their participation perceived P2P to be contributing to the community [43]. A sense of community or collective identity was perceived by users to have been reinforced by P2P energy sharing activities in three pilot sites in Portugal [19].

For some study respondents, local benefit is closely connected to the value of energy independence described above. All but one of the households interviewed in the Quartierstrom trial valued locally optimizing supply and demand and some referred to the importance of achieving independence of energy supply from other regions [43]. A UK survey likewise found that scenarios in which a higher proportion of energy needs are met by P2P trading appeared more attractive to participants [44]. An ethnographic study on a peer-to-peer energy pilot in rural India reported participants' desire and ability to interconnect the P2P energy models with a local economy of goods and services, such as agricultural yields, labour, and dairy production [45]. Further, the study reported the attractiveness of $\mathrm{P} 2 \mathrm{P}$ energy for providing clean energy access to off-grid and remote areas in the global south [46].

However, the desire for energy needs to be met locally appears to be in tension with a concern about security of supply. This is suggested by the findings that a neighbourhood- 
level P2P offering was less popular at $75 \%$ than at $50 \%$ of consumption needs met [44], and that German respondents in both national and Allgäu samples preferred regional electricity over local electricity [38]. Mengelkamp and colleagues [38] note that while feedback from the survey indicates that security of supply is an issue, other factors (such as an assumed higher price of local electricity or a preference that electricity generation infrastructure is not located locally) could explain this finding.

\subsubsection{Sharing and Social Relationships}

The literature also shows that people interested in participating in P2P, CSC and TE models value that it involves sharing electricity, underlining that not only monetary but also ideological reasons motivated participation [19,34-36,45]. This appears to be related to the value of community above, and indeed people's preferences for participation in energy trading are mediated by the social relations in which the trading occurs. The ethnographic study of P2P energy trials in India identified the significance of 'mutuality' or social relations in local energy trading and sharing [46]. The study identified that householders, when they get to structure P2P energy exchange, operate within two dialectically connected value contexts, social relations and self-interest, and accordingly participate either for the sake of social relationships or for the sake of making a material gain. Prosumers sharing energy with others were more likely to accept 'intangible' and 'in-kind' returns when providing energy to 'socially intimate' and 'socially close' rather than 'socially distant' recipients [1]. The intangible returns are built upon the notion of togetherness, friendship, love, solidarity and different ways of bonding with others [45], reflecting considerations of co-inhabitance and co-dependency between households [46]. In such cases, people seem to value their enduring social relationships more than making any monetary or material gain [45].

Australian P2P trial participants expressed in focus groups a 'high interest in social equity' and the initial hope that they would be able to 'support and sell to selected individuals within the community' - which were not matched by the autonomous P2P offering that they were offered, which they 'considered overly market driven' as opposed to community-led [39] (p. 10).

\subsubsection{Environmental Responsibility}

P2P, CSC and TE models are widely seen to hold environmental benefits. This perception was identified as the main motivating factor in Dutch focus groups [29] and has been shown to increase willingness to participate among German survey respondents for whom such considerations are important $[35,42]$. Environmentalism was also perceived by users as an existing social value that was reinforced by P2P energy sharing in three pilot sites in Portugal [19]. Even when positive economic return is a consideration, some study participants express a strong preference for renewable energy [29]. For prospective participants, environmental benefits are often cast in ethical terms, including responsibility to future generations [29], and cultural terms, including subscription to a sustainable lifestyle [34]. The environmental rationale was also raised by eight of nine of the interviewed households that had already participated in the Quartierstrom trial [37].

Electricity grid balancing and stability is a related issue, and some study participants consider it important to ensure that renewable energy trading or self-consumption models do not exacerbate network management challenges. For example, Smale and Kloppenburg [29] report that in a context of concern that moves towards self-sufficiency and autonomy of renewable energy generation may neglect the costs of maintaining the power grid, workshop participants were keen to consider energy platforms that prevent grid problems rather than exacerbate them. In other words, they expressed the need to focus on grid resilience in designing a local electricity network dominated by renewable energy.

\subsubsection{Participation and Purpose}

At a more general level, a value associated with P2P, CSC and TE-and one that connects in various ways to the other values that have been outlined above-is that of new roles 
and relationships that the participants can have in these models. This tends to be expressed as a desire for greater agency in the energy transition. For example, 'the trial participants view themselves as an active part of creating the niche by contributing to learning and locally implementing the new business model as innovators and legitimators' [39] (p. 12).

There is some suggestion that people value active engagement with their energy generation and consumption as an end in itself [34]. For example, most of the Quartierstrom participants valued being able to read their load profile [43] and participants in a distributed ledger trial appear to have used the user interface to learn more about their energy use and to consider further DER investments, such as a battery [41]. UK residents interested in renewable energy, but not yet participating in a P2P, CSC or TE model, who were interviewed by Wilkins et al., spoke about it 'as having the capacity to support changing user relationships with policy makers and energy supply companies', and specifically to offer an 'alternative to top-down and centralized control over the UK's energy challenges' [34] (p. 6); emphasis in original. This desire for greater agency in the energy transition has also been observed in three Portuguese P2P energy sharing pilots [19].

There is mixed evidence about the extent to which people value the possibility of social comparison, or comparing themselves with their peers, in P2P and TE models. Some participants of the Quartierstrom trial appreciated the element of gamification and competition [43]. In a P2P trading trial in Madeira, the weekly ranking comparison with other users was one of the most popular features, and some reported attempting to use a higher share of renewable energy to improve their ranking [41]. Counter to these findings, Dutch workshop participants were wary of 'big neighbour' scenarios in which neighbours would be able to monitor and compare their performance [29].

There is also mixed evidence about the dynamics of social relationships that are developed between peers and the extent that these are new forms or built on established relationships. The potential for structural forms of inequality such as race, class, gender or caste differences to be reproduced through these markets has been raised in the literature. For example, the trial studied by Singh et al. [46] showed that participation in P2P exchange can strain and damage existing social relationships.

Various studies either directly or indirectly suggest the anonymity (or otherwise) of participants in P2P, CSC and TE models may play an important moderating role in the delivery of social value. In cases where the development of new or existing social relationships is core to the model (such as in Singh et al. [46]), transacting anonymously would be inconsistent with this objective, as was found by Wilkinson et al. [39]. Indeed, existing schemes such as SunContract [61] and powerpeers [62] advertise the ability to transact with friends and loved ones. However, survey findings suggest that preserving anonymity was a valued characteristic of blockchain technology in the context of energy trading [44]. And some of the inequalities which emerge from the introduction of such trading may be attributable to people's preference to trade with some individuals or groups more than others. For example, a review of evidence on the distributional impacts of the accommodation sharing service Airbnb found consistent evidence for discrimination on the basis of factors such as race and gender when personal characteristics of participants are revealed [63].

The forms of social value identified in the literature are summarised in Table 3 and Figure 5.

\subsection{Economic Value of P2P, CSC and TE Models}

One of the main forms of economic value associated with P2P, CSC and TE models referred to in the literature is the potential to make electricity less expensive than in a business as usual (BAU) scenario, including by making renewable energy more profitable and 'supporting new and better mechanisms for return-on-investment beyond government subsidies', as anticipated by the respondents interviewed by (Wilkins, Chitchyan and Levine [34] (p. 6). While there are many modelling studies that explicitly calculate expected economic impacts on participants in P2P, CSC and TE models, our review focused on 
(a) economic value as a motivator for participation, and (b) realised economic value in real-world examples.

Table 3. Summary of social value dynamics of P2P, CSC and TE models.

\begin{tabular}{ll}
\hline \multicolumn{1}{c}{ Concept } & \multicolumn{1}{c}{ Description } \\
\hline Energy independence & $\begin{array}{l}\text { Autarky refers to energy self-sufficiency through reliance on } \\
\text { self-generated energy and limited interaction with wider electricity } \\
\text { system (including self-assured continuity of energy supply) } \\
\text { Autonomy is seen more in terms of social agency, either though } \\
\text { ownership, involvement in decision making or independence }\end{array}$ \\
$\begin{array}{l}\text { Autarky } \\
\text { Autonomy }\end{array}$ & $\begin{array}{l}\text { Benefits that are created and retained in specific geographic } \\
\text { communities or communities of practice. These benefits may be social } \\
\text { or of economic in nature }\end{array}$ \\
\hline $\begin{array}{l}\text { Local benefits/provenance } \\
\text { relationships }\end{array}$ & $\begin{array}{l}\text { Developing new and existing social relationships and reciprocity } \\
\text { through the sharing and/or trading of electricity }\end{array}$ \\
\hline Environmental responsibility & $\begin{array}{l}\text { Shared ethical values which are derived from the environmental } \\
\text { benefits of renewable and sustainable energy systems }\end{array}$ \\
\hline Participation and purpose & $\begin{array}{l}\text { Value derived from the participatory process of developing and } \\
\text { trading renewable energy }\end{array}$ \\
\hline
\end{tabular}

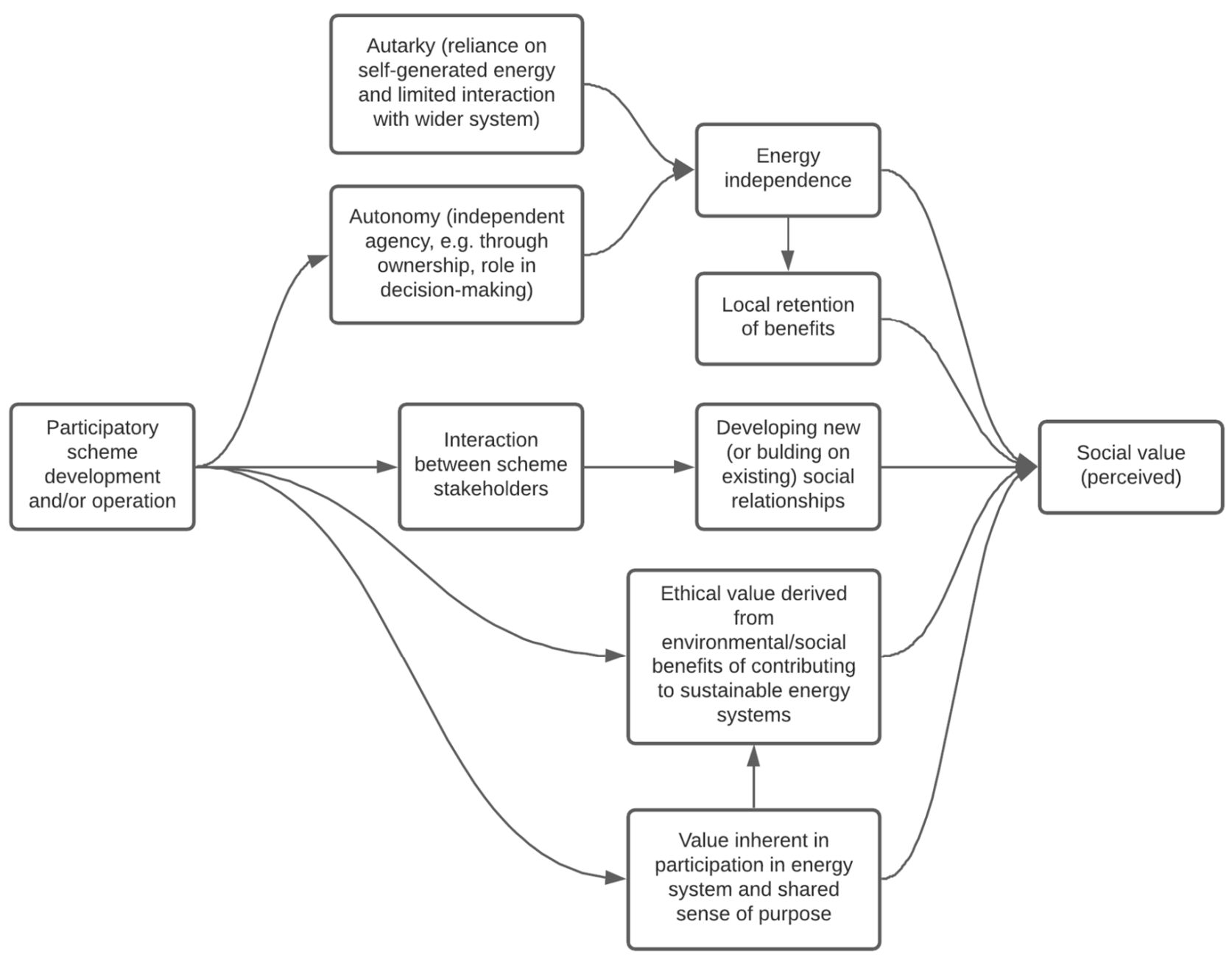

Figure 5. Elements of perceived social value as revealed in this review. The arrows represent our interpretation of how they are likely to relate to each other. 
The literature holds mixed findings about the importance of economic considerations for willingness to participate in P2P, CSC and TE initiatives. The financial factor was identified as the most important factor for willingness to participate among German survey respondents $[36,38]$ and the primary motivator for energy sharing among prosumers in Bangladesh [31]. Economic incentives had also been important for participants upon entry into the Quartierstrom trial, with 'most' of those interviewed stating that they had hoped to be able to sell electricity at a higher price than they were being paid to export it to the grid [43]. Some of the participants interviewed also valued the lower grid fees that were implemented in the project [43]. For the 'vast majority' of respondents of the German national survey about participation in 'energy communities', lower electricity costs are a condition of participation; only a small minority said that they would participate even if it was more expensive [36]. Based on their experience implementing P2P initiatives, some German experts interviewed also perceive profitability for the prosumer as a 'necessary condition' for their willingness to participate [47]. The importance of financial factors is also supported by the observation that respondents from a national German sample-although not a regional Allgäu sample-were more willing to spend time inputting monthly data in a local energy market than accept higher prices [38]. In an experimental study, of the 223 survey participants interested in P2P, 117 made trading choices based on prices-a larger cohort than that driven primarily by autarky referred to above [30].

In contrast, Scuri et al., found that economic benefits seem 'not to be a strong motivator' [41] (p. 101). Mengelkamp et al. [42] report that, contrary to their hypothesis, no statistically significant influence of price consciousness for willingness to participate in local energy markets was found. The authors note, however, that the survey didn't explicitly specify whether money could be saved in local energy markets, and this could explain the lack of significance. Interestingly, the importance of financial considerations appeared to change throughout the Australian trial examined by Wilkinson et al.,: 'during the focus group discussion, only $25 \%$ of respondents stated that they were motivated to join the trial to save money or by the expectation of being financially better off, and this was mentioned apologetically' - but the willingness to participate shifted after the introduction of a P2P tariff structure that indicated likely financial losses, and fewer than half of the participants remained in the trial [39] (p. 8 and 12). This seems to suggest that it may not be important to people to be better off, but it is important to them to not be worse off.

Analysis of survey data by Dukovska, Paterakis and Slootweg [48] suggests that desire for independence from utilities interacts with financial considerations. Among the subsection of respondents who had expressed a general concern about electricity bills, they found a high correlation between a concern about utility rate increases and a desire for independence from their utility. Indeed, the value that people ascribe to energy independence appears to mediate their perceptions of the economic value of energy: highlighting the autarky benefits of energy storage systems to experimental study participants made them value their own self-generated energy more highly than the energy available for purchase from neighbours, compared to a control scenario in which these benefits are not highlighted [28].

The literature shows that economic value has been realized in P2P, CSC and TE trials. The economic feasibility of P2P energy sharing initiatives for both consumers and prosumers was demonstrated in real-life settings in Portugal, where an advantageous P2P energy tariff was designed for electricity traded within low voltage energy networks [49]. Analysis of the trading in the Quartierstrom trial showed that both sellers and buyers benefitted from the P2P transactions, 'as they trade at a price that is below the price that the consumer would have to pay to the utility company and above the revenue that the prosumer would earn for feeding into the grid' [32].

The trial in Japan demonstrated that, compared to a P2P bidding strategy with fixed prices, a bidding strategy based on the current price of the electricity stored in the battery of each standalone system resulted in 55\% fewer deals due to fewer available matches in the preferred price range of participants and, in turn, a predictable pattern of stable peaks that indicate higher prices in comparison with the case of fixed pricing. However, the increased 
utilization of self-generated electricity achieved with the bidding strategy resulted in a $10 \%$ decrease in energy spending in households with high levels of consumption, and $7 \%$ decrease in medium and low consumption households of average daily consumption of more than 100 watts [33]. Other, less direct economic benefits can also follow, e.g., in India, local businesses benefit from being able to run larger loads [31].

Wörner et al., observe that 'the participants' real-world price settings in the field study considerably deviate from their self-reported preferences indicated in the pre-experimental survey' [32] (p. 11) - suggesting that the way that economic value interacts with other forms of value outlined in this review in the perceptions of P2P, CSC and TE model participants is complex, unstable, and cannot be analysed based on self-reported preferences alone. In addition, Singh et al. [45] describe the use and relevance of non-financial returns, such as in-kinds and intangibles for accessing energy through P2P models, and how a dialectic tension between market and non-market values are at work in P2P energy exchanges. Further, the study describes contexts where participants refrained from using any financial payments as they considered such payments to be morally and culturally inappropriate to be invoked in P2P energy exchange with 'socially intimate' peers.

The forms of economic value identified in the literature are summarised in Table 4 and Figure 6.

Table 4. Summary of economic value dynamics of P2P, CSC and TE models.

\begin{tabular}{ll}
\hline \multicolumn{1}{c}{ Concept } & \multicolumn{1}{c}{ Description } \\
\hline Self-consumption of renewable electricity & The utilization of self-generated electricity at zero marginal cost \\
\hline Reduced electricity import costs & Achieving lower electricity import prices than BAU \\
\hline Improved electricity export prices & Achieving higher electricity export prices than BAU \\
\hline Costs placed on wider energy system & The economic impact on the wider electricity/energy system \\
\hline Local economic development & The creation of local economic benefits/disbenefits \\
\hline
\end{tabular}

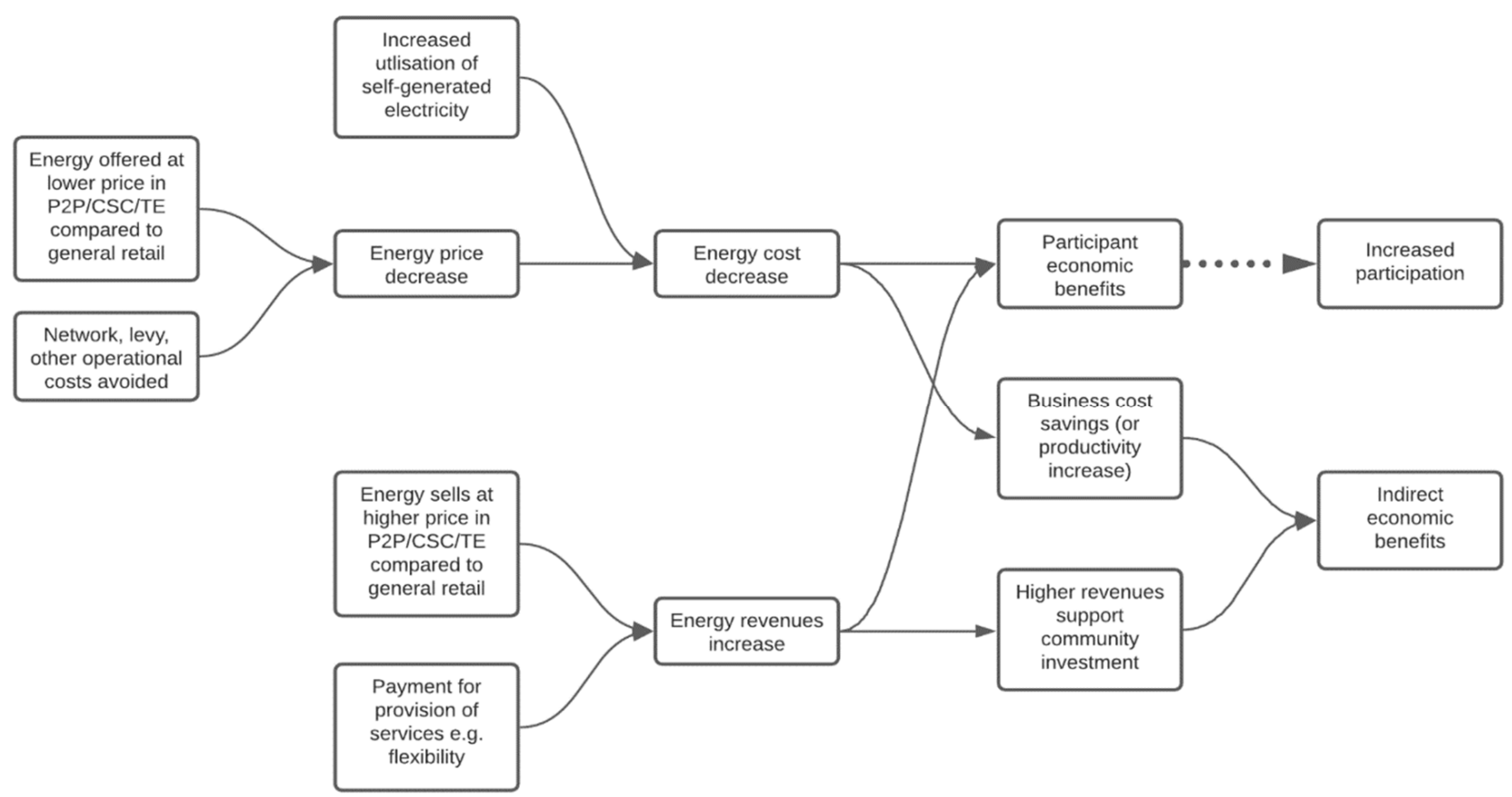

Figure 6. Elements of economic value as revealed in this review. The arrows represent our interpretation of how they are likely to relate to each other. The dotted line represents mixed evidence in support of this connection. 


\section{Factors and Conditions of P2P, CSC and TE Model Uptake and Success}

Whether P2P, CSC and TE models are taken up by energy users, and the forms of value outlined above are realized, depends on a range of factors and conditions.

\subsection{Participant Characteristics and Preferences}

\subsubsection{Willingness to Participate}

The literature does not offer a clear picture about whether people are interested and willing to participate in P2P, CSC and TE models. Relatively few studies quantify general willingness to participate. Most participants in a survey of German customers were open to participating in $\mathrm{P} 2 \mathrm{P}$ trading $(74.5 \%$ of participants had a neutral or positive attitude towards P2P trading) [35].

Of the 301 participants in the study by Hahnel et al. [30], 233 participants $(77.4 \%)$ indicated general willingness to participate in P2P trading, while the remaining 68 participants (22.6\%) indicated that they were not willing to participate as a consumer in P2P energy trading after having received detailed information about the concept. In Fell et al., 2019, stated willingness to participate in P2P energy trading in a nationally representative sample of 2064 UK survey respondents ranged from $54-67 \%$ depending on conditions such as localness of peers and proportion of demand covered by P2P trading.

Willingness to participate can be expected to vary between regions, as supported by the observation that the Allgäu residents were more willing to participate than the German national sample [42]. Interviews with people involved in running various local electricity sharing demonstration projects in Germany and Australia reported the absence or even the opposite of social, cultural and behavioural barriers to the adoption of the model [50].

The literature indicates that the people most willing to participate are younger $[30,38,44]$ (which Mengelkamp et al. [38] define as less than 60 years of age), while the 40-69 age range was found to be most open by Hackbarth and Löbbe [35]. Willing participants also tend to be more educated [30,35] and less politically conservative [30].

In terms of household characteristics, larger households appear to be more willing to participate $[30,38]$. Some studies have found that the survey respondents who are willing to participate in energy communities tend to be homeowners [36]; while, in contrast, those who rent their homes were found by [35] to be more open to P2P trading than homeowners.

The literature suggests that people willing to participate in P2P tend to be more financially well-off; those who participated in the Australian trial, for example, were financially secure [39]. On the other hand, again challenging most of the existing literature, Hackbarth and Löbbe [35] found that having a lower income correlated with openness to P2P trading - a finding that they note is in fact in line with findings from the sharing economy research.

\subsubsection{Engagement in Technology and Renewable Energy}

Interest in renewable energy is also high among people willing to participate in $\mathrm{P} 2 \mathrm{P}$, reflecting the value of environmental benefits ascribed to P2P, CSC and TE modes above. The most significant demographic factor associated with interest in participating among UK survey respondents was a concern about climate change [44]. High levels of interest in transitioning to decarbonized energy systems and knowledge of renewable energy characterized Australian trial P2P participants [39]. In contrast, Hahnel et al. [30] did not find a systematic relationship between 'biospheric value' and willingness to participate in trading.

P2P trading was found to be more attractive for individuals who report a positive view of distributed energy resources such as PV and battery storage and willingness to invest in relevant infrastructure to enable P2P electricity trading [30] and who are thinking of purchasing it [35]. Interestingly, those who already have such DER have been found to be both more interested [44] and less interested [35] in P2P trading. The latter study notes that this may be because P2P trading may require prosumers to give up a feed-in tariff-which is guaranteed for some time to come in Germany, where the study was conducted, making 
the 'switch to an unknown and economically less predictable market-based option in the short term' less attractive [30] (p. 11).

Reflecting the value ascribed to active engagement with energy discussed above, willingness to participate is higher among those who have an interest in innovation and technology and are early, 'pioneering' adopters of new technologies [35,36,39,42,44], while many of the participants of existing P2P, CSC or TE projects considered in the literature reviewed here are described as early adopters [43,51].

Research participants appear to respond differently to the different elements of technology involved in P2P trading; for example, distributed ledger technology can elicit no widespread concerns or effect on willingness to participate [41,44], but it can make P2P less appealing for people who perceive it as untrustworthy or unsuitable for their scale of trading [52]. Association with Bitcoin in particular could make blockchain-enabled P2P schemes less appealing to prospective participants $[41,44]$.

\subsubsection{Complexity, Transparency and Trust}

The perceived general complexity of P2P trading was not discouraging for the earlyadopter cohort in the Australian trial [39], but others have expressed that they would not want P2P to introduce more complexity [31,41]. Easy implementation also appeared as an important factor for purchase of a P2P electricity trading product in a survey of German customers [35] and is valued by the category of study participants who purchase energy, but do not generate and trade their own [52].

Preferences regarding the role of automation in facilitating participation in P2P, CSC and TE models appear varied and complex. Respondents in the study by Wilkins et al., perceive algorithms to make it difficult to understand what data is being collected and how it the system is going to operate, but 'automation could also be seen as empowering, if participants could indicate their preference: they described how users could set up the system and then carry on with their lives without further effort of concern' [34] (p. 7). While participants in the workshop ahead of the Quartierstrom trial expressed a preference to be able to set their own prices [37], when it came to the actual trial, 11 of the 28 households chose to actively participate and 13 opted for automated pricing [43]. All participants in the Madeira trial selected the automatic mode, several reported feeling reassured that they had the opportunity to manually define criteria for trading [41].

Financial transparency was identified in a workshop with participants as an important feature of the user interface being designed ahead of the Quartierstrom trial [37]. Privacy and data security is another issue evident in the literature. Some survey respondents have indicated that they would prefer not to allow their data to be freely accessed and used [38]; on the other hand, Scuri et al. [41] identified privacy of data shared via distributed ledger technology as a 'minor concern' raised by only one of the study participants.

Research participants' preferences for the P2P, CSC or TE coordinating body varied somewhat. A UK online choice experiment showed that the preferred coordinating entity for a P2P scheme was a council, followed by energy supplier, community energy group and social media company [44]. German survey respondents likewise ranked relatively low the options of energy cooperatives [36] and telecommunication company [35], while their most preferred entity is energy provider [35] or municipal—followed by regional—utility [36].

Table 5 summarises the influence of participant characteristics and preferences on P2P, CSC and TE models.

\subsection{Model Design and Implementation}

\subsubsection{Household Engagement}

Crucial to the success of P2P, CSC and TE models is the engagement of the participating households. Levels of awareness about energy community concepts were found to be low among German survey respondents: only 3\% of the respondents were familiar with the concept of energy communities or aware of specific offers currently available [36]. 
The literature indicates that levels of household participation in P2P, CSC and TE models have been improved by engagement strategies. Mengelkamp et al. [51] attribute the 'well-developed' public acceptance and customer participation in the Brooklyn Microgrid to public relations work as well as demographics. Klein et al. [53] show that, in three Portuguese pilots, dedicated user engagement strategies were effective in engaging approximately half of the users who had initially been identified as 'indifferent', primarily by building their awareness and capacity to participate by trouble-shooting issues. They also note the importance of a thorough recruitment process 'to evaluate individually and a priori whether each enrolled household was technically eligible to participate in the project' and thereby avoid participants experiencing technical problems once already participating, as demonstrated in one of the three pilots they examined [53] (p. 11).

Table 5. Summary of the influence of participant characteristics and preferences on P2P, CSC and TE models.

\begin{tabular}{ll}
\hline \multicolumn{1}{c}{ Concept } & Description \\
\hline Regional differences & $\begin{array}{l}\text { Social, cultural and institutional differences between regions may } \\
\text { drive different attitudes to the adoption of P2P/CSC/TE }\end{array}$ \\
\hline Demographic factors & $\begin{array}{l}\text { Younger, wealthier and highly educated people who are less } \\
\text { politically conservative tend to be more interested in these models }\end{array}$ \\
\hline Engagement in technology and renewable energy & $\begin{array}{l}\text { People who have concerns about climate change, already have } \\
\text { involvement with decentralized energy systems or are technology } \\
\text { early adopters are all more likely to be positive as to the adoption of } \\
\text { P2P/CSC/TE }\end{array}$ \\
\hline Complexity, transparency \& trust & $\begin{array}{l}\text { The complexity of P2P/CSC/TE models is a potential issue, with } \\
\text { trial participants tending to favour automation over more active } \\
\text { participation. Trial participants also commonly express concerns } \\
\text { about financial transparency and data protection, with different } \\
\text { levels of trust for different types of coordinating actor. }\end{array}$ \\
\hline
\end{tabular}

Conversely, a lack of appropriate engagement can impede energy model uptake and success, as Wilkinson et al., describe of an Australian trial in which 'the initial design of the P2P trading model was developed with little consideration of user input and the co-production process was weak, resulting in user criticism of poor system design with inappropriate pricing' [39] (p. 12).

\subsubsection{Community Building}

'Fostering a sense of being part of a community' is also identified as a necessary step in establishing P2P, CSC and TE models, based on householders' experiences using a P2P trading platform PowerShare in Madeira [41]. According to the authors, this could help to reduce the impact of the absence of a third-party central authority in whom participants could otherwise place their trust.

\subsection{3. (Mis)-Alignment of Project Objectives and Interests}

The literature indeed suggests that interactions among the actors-the household participants, coordinating entity, competing energy providers, and so on-can influence the uptake and potential success of P2P, CSC and TE models. A key theme apparent in the sources reviewed here is that of differing interests and expectations among actors.

Wilkinson et al. [39] identify in the Australian trial 'a misalignment between how the consortium members [a city council, a land developer, two universities, a blockchain start-up, and an electricity generator, network operator and retailer] perceive the participants' involvement and how the participants want to be involved'. As discussed above, the trial participants wanted to play, and saw themselves playing, an active role. The authors consider this discrepancy to be likely 'a main reason for the high dropout rate and the perception of weak trial design' [39] (p. 12). This points to the need for clarity and agreement about the role of stakeholders, which was also found to be important in the 
trial in Bangladesh [31], where trial participants expressed concerns based on previous experiences that models of shared ownership of generation and storage assets can impede the clear allocation of responsibility for asset maintenance.

\subsubsection{Competition and Tensions between Actors}

The actors involved can also have conflicting interests that can undermine the uptake and success of a P2P, CSC or TE model. In the Australian trial, the project consortium placed more emphasis on stabilizing prices and addressing peak demand, while (as mentioned above) the participants had interests in advancing 'social equity and sharing energy within the community, aspects that the eventual market design failed to deliver' [39] (p. 12). Another tension was apparent in this case with respect to the economic value realized for the users: the pricing structure was only revised to the extent that it kept utilities in a comfortable position but led to users paying more for P2P trading than in the BAU scenario [39]. Expert interviews have also highlighted how actors such as DNOs may be reluctant to support P2P trading because it could reduce the obligations of participants to pay grid-related fees, for example [50].

The viability of other real-world trials has been affected by competition between the business interests involved in the P2P, CSC and TE model or operating around it. For example, the minigrid run by the private utility company Purobi Green Energy on Sandwip Island in Bangladesh encountered problems when a rural electrification board built a diesel-powered electricity plant, offered subsidized rates, undercutting the minigrid's rates and threatening its survival until the diesel-plant operators agreed to avoid competing in the same area [54]. A minigrid trial in Nepal encountered a tension between two bodies involved in running the minigrid, the plant functional group and the cooperative body, because the former sought to alter the Power Purchase Agreement in favour of the consumers but not in the interests of the minigrid. This tension and the dissatisfaction of staff within both bodies 'affects the management of the existing system' [55] (p. 131921).

Table 6 summarises the influence of model design and implementation on P2P, CSC and TE models.

Table 6. Summary of the influence of model design and implementation on P2P, CSC and TE models.

\begin{tabular}{ll}
\hline \multicolumn{1}{c}{ Concept } & \multicolumn{1}{c}{ Description } \\
\hline Household engagement & $\begin{array}{l}\text { Successful trials of P2P/CSC/TE models have undertaken } \\
\text { extensive household engagement activities and ensured strong } \\
\text { participation in the trials }\end{array}$ \\
\hline Community building & $\begin{array}{l}\text { Studies also highlight the importance of relationship building } \\
\text { within the host communities }\end{array}$ \\
\hline (Mis)-alignment of project objectives and interests & $\begin{array}{l}\text { Studies identified the importance of aligning the objectives of } \\
\text { the trial's designers with the host communities }\end{array}$ \\
\hline Competition and tensions between actors & $\begin{array}{l}\text { Competing interests between project stakeholders and wider } \\
\text { incumbent actors and institutions can be an important factor in } \\
\text { the success and scalability of P2P/CSC/TE models }\end{array}$ \\
\hline
\end{tabular}

\section{Discussion}

This literature review encompasses all the current research identified with our systematic search methodology. We have identified a range of social and economic values associated with P2P, CSC and TE models. However, as stated previously, these values are intrinsically context specific. Hence, it is relevant to emphasize that these findings are bound to the context where the research studies were conducted, most of them in developed countries in Europe, the US and Australia, as shown in Figure 2. Furthermore, as depicted in Figure 3, the majority of case studies focus on P2P energy trading, investigating the business and technical feasibility of these energy models. Consequently, there could be missing social and economic values or nuances arising from the unaccounted 
model configurations. In this sense, we do not intend to generalize the values identified in this review to energy users across the world nor claim that the review exhausted the whole range of user-centred energy models. On the contrary, we highlight the importance of further research and piloting, including in developing countries, and testing different model configurations to explore how user values and perceptions vary with context (i.e., type of electricity market and socio-economic conditions).

\subsection{Conflicts between Values}

The sources of social and economic value we have identified in this review provide some insight into how P2P, CSC and TE schemes could be designed and communicated to attract participation. However, it is important to be clear that unlocking or promoting some sources of value will likely have to be traded off against access to others.

\subsubsection{Social vs. Economic Values}

The literature reviewed suggests that one source of potential conflict arises to the extent that the more participants value independence (especially autarky), the less inclined they may be to actually make excess generation available to others rather than using or storing it themselves (e.g., [28]). This in turn would reduce supply, increase purchase prices, and reduce savings potential for consumers. Similarly, the more possibilities there are for social connectivity to be built through the scheme, the greater the risk of challenges such as conflicts and discrimination.

This review has also underlined that a predominant feature of P2P models is the essential and mediating role of market design. These models indicate a hegemony of market-ideal' [64] that ignores and sometimes opposes the non-market potentials, possibilities, and opportunities of P2P energy in particular and decentralized energy in general. Similar points have been raised by Singh [64]: 'the contemporary understanding of energy exchanges presumes universal primacy of logic of the market where the householders engage in competitive buying and selling of energy'. The existing literature is limited in the theoretical and conceptual discussion on P2P models that goes beyond the logics and structures of the market. We believe this will be crucial for realizing non-market forms of P2P energy exchanges and enabling other social values through these models. Moreover, the interdependence of market-based energy exchange on non-market mechanisms seems to be a fruitful research direction $[45,46]$. We recommend engagement of P2P scholarship with perspectives from economic anthropology, cultural economics and economic sociology as these disciplines have developed considerable theoretical and conceptual knowledge on non-market exchanges.

\subsubsection{Prosumer vs. Business (Retailer, Network) Values}

With economic factors being a significant motivator, the financial models in each P2P, CSC or TE trial in the literature reviewed have had to determine an appropriate allocation of costs between different groups of stakeholders with competing interests. Furthermore, as these trials required the continued participation and cooperation of their user and prosumer participants, understanding their expectations was essential to its success. An individualist interpretation of 'energy independence' was the dominant perspective in some of the trials reviewed $[31,36,38]$. Consumers and prosumers expected that participation would lead to lower electricity bills [38,47], either as reductions in imported energy costs or higher prices for exported energy [32,47] rather than improvements in autarky [30].

From the retailer and network operator perspective, however, their profit margins would be eroded if this trading activity did not also lead to reductions in operating costs or increased revenue above any additional costs incurred. As retailers and network operators are critical stakeholders with decision making power, they retain an outsized ability to set customer price conditions and transactional costs that could be used to protect their margins [50], but at the expense of any financial advantage that consumer and prosumer participants had expected. In the trial described by Wilkinson et al. [39], 
this led to participants opting out soon after joining which compromised the success of the trial. These mismatched expectations drive tensions between customers and utilities and highlight the importance of establishing a suitable compromise between the costs and benefits for each stakeholder [32,49].

P2P, CSC and TE models provide the means to cater to individual preferences that can, furthermore, differ between different consumers and prosumers. These studies also highlight that determining an appropriate allocation of costs between different groups of stakeholders with competing interests is a particularly challenging problem. While in some instances, trials have been able to find a suitable compromise at the individual level $[32,49]$, this may not always be possible. A better understanding of the social values of the individual trial participants and their expectations around community benefits may be leveraged to provide additional degrees of compromise that are less reliant on economic self-interest (e.g., reducing costs for local self-consumption over maximizing the value of exports). This creates an opportunity to extend the benefits of P2P, CSC and TE models beyond the individual to also include local economic development.

\subsubsection{Value of Business as Usual (BAU) vs. New Opportunities}

Another key finding of this review is that participants did not want to be worse off in a P2P, CSC or TE model [39], which means that BAU conditions are an important factor to consider. With prosumers looking to improve the value of their exports, expected BAU conditions are as important as the available value streams. Therefore, if prosumer BAU conditions are currently deteriorating (e.g., decreasing or end-of-contract feed-in tariffs), it becomes easier to establish economically beneficial arrangements with counterparties in the trial (e.g., consumers paying less than full retail for local self-generation while providing prosumers with a higher value for their exports). Therefore, the timing of P2P, CSC and TE trials need to also consider the current BAU environment of its potential trial participants.

\subsection{Forms and Mechanisms of Value Generation}

The systematic screening methodology outlined in Section 3 produced a study sample dominated by papers focussed on P2P models, and the conceptual delineation between P2P, CSC and TE remains contested in the literature. This means clear differentiation between the different forms of social and economic value between P2P, CSC and TE models should be treated with caution. However, some emerging features that are highlighted by (Watson and Gorbatcheva (forthcoming) can be understood through the dynamics of social and economic value observed in the studies we reviewed, as described in Tables 3 and 4.

CSC models are often characterized at the smallest scale, and therefore tend to be bound to specific geographical locations and low voltage networks. These models focus on increasing self-consumption of renewable electricity as their primary form of economic value creation [13], although may also emphasize local economic development within discrete locations or communities [25]. Because of this explicit community focus, CSC models are also likely to foreground local benefits and provenance above more system focussed attributes and aim to strengthen social relationships. The focus on self-consumption rather than trading, also seeks to maximize autarky and a degree of independence from the wider energy system [65]. This may also support a broader worldview and social movements predicated on self-sufficiency, self-governance and a degree of isolation from wider society [13].

By contrast, discussion in TE models may emphasize system level interactions, with the aim of optimizing the operation of electricity networks as a whole. A common theme is the aggregation of multiple sites of generation and flexibility to provide services to system operators [56] helping to reduce costs placed on the wider energy system. The optimization of these systems may therefore see an important role for aggregators, and therefore place more emphasis on price signals than social relationships [8]. However, because these models engage a large network of users, they may engender feelings of participation and purpose in a wider section of society than the small segment who may be more proactive members of energy communities. 
P2P models perhaps represent the most radical departure from the current electricity system. Because these models enable direct trading between peers, some proponents argue they may eventually obviate the need for traditional utilities and system operators altogether. Thus, P2P advocates may foreground the value of energy independence but emphasize the social values of autonomy through P2P trading, rather than a more isolationist focus on autarky [39]. Consequently, P2P models seek to create economic value both through improved electricity export prices and also reduced electricity import costs through the optimisation of supply and demand through real time price signals [15].

\subsection{Open Challenges and Research Directions}

The different forms and mechanisms of value creation of the three models also reflect the broader political context in which trials are imagined, designed and deployed. In addition to the empirical evidence, the review process also engaged some theoretically oriented literature that questions the power interests shaping innovation processes, market rules and engagement processes which all shape the forms of value identified and pursued. This literature signposts future research directions, such as understanding how these new forms of energy provision could reproduce structuring inequalities such as gender, class and race, provide fresh territory for speculative capitalism and compound or create distributional impacts.

\subsubsection{Distributional Issues}

The digital platforms and algorithms that make P2P, CSC and TE models possible have been flagged as turning energy markets into new examples of 'platform capitalism' [66]. Although platforms promise consumer cost benefits and system efficiencies, they can create new 'systemic irrationalities and externalities', e.g., in the way that Uber has increased the numbers of cars on streets at the expense of public transport and created customer cost savings at the expense of workers' rights [67]. Similarly Fell [63] has considered how P2P trading could lead to distributional inequalities by looking at the mechanisms through which AirBnB users unintentionally reproduce race and gender-based discrimination. These new concerns add to the existing inequalities within energy markets that mean lower income, less digitally able or socially, politically, geographically and economically marginalized groups fail to access the cheapest or cleanest available energy.

DERs are still prohibitively expensive, and digitalization is still lacking for most energy users across the world. These models, if not thought through appropriately, may widen the 'energy wealth' gap between poor and rich. However, methods and approaches are available that explicitly aim to innovate new energy services and technologies that facilitate inclusion and equity. An energy justice framework may, for example, offer purchase on such challenges by providing an approach that seeks the fair distribution of both the benefits and burdens of energy services [68]. Hiteva and Sovacool [69] demonstrated with four case studies how embedding energy justice into energy business models can bridge the gap between business values and social values through local, contextually dependent drivers. Understanding the diverse range of social and economic values and preferences of users is critical to the design of inclusive user-centred energy models.

\subsubsection{Value Quantification}

Since only part of the overall value created by society can be assimilated into market relations, this paper highlighted the need to demonstrate the real impact of what can be achieved with P2P, CSC and TE models instead of just what is easily quantifiable. For that, social values were considered core outcomes of user-centric energy services, rather than just an incremental externality. Some of the studies reviewed situate the forms of value generated through the examined cases within wider debates on normative and alternative value [13], or non-market spheres of exchange [46]. These show that in addition to measuring values that are easily quantified it is equally important to understand and capture unquantifiable values such as a sense of community pride, greater environmental 
awareness and feelings of comfort and convenience [70]. Although it is inherently difficult to quantify the unquantifiable, capturing these qualitative details that are more often perceived will reveal the true benefits that are intrinsically linked and contextualizes the full narrative of the value created in a self-sustainable P2P, CSC or TE system. This means moving from a strict profit-oriented perspective focused on economic outcomes towards a wider perspective that also encompasses non-market outcomes, as discussed above.

\subsubsection{Citizen Engagement}

In line with research illustrating that autonomy and empowerment are relevant drivers of participation in P2P communities [37,39], it is important to identify and examine opportunities to integrate citizens in the design and operationalization of the communities. Future research based on stated preferences and real-life behaviour examined in trials should investigate means to increase citizen involvement at various stages of community development. Thus, it is an intriguing question whether early involvement in the design of energy communities impacts citizens' participation in later phases of community development (i.e., increases active participation, e.g., in energy trading). Moreover, it is important to analyse how user preferences beyond financial aspirations can be integrated into the decision-making process within future communities [71]. User-centred trading algorithms and autonomous agents incorporating user preferences could enable energy trading that fulfils user preferences by concomitantly reducing demand in everyday life. Future interdisciplinary research needs to examine both user preferences and heterogeneity in preferences as well as measures to integrate identified factors in ICT for P2P trading.

\section{Conclusions}

In this article we have presented the findings of a systematic review of the literature on the economic and social value associated with the P2P, CSC and TE models emerging in energy systems in several parts of the world.

We defined social value as what people deem important to them. The review identified evidence for a variety of sources of social value. Value is attached to the independence that P2P, CSC and TE models could afford to participants, whether through autarky (selfreliance with limited interaction with others where necessary) or autonomy (independent agency through e.g., ownership and decision-making). Connected with this, value is also placed on the potential of P2P, CSC and TE models to help retain benefits in the locality where they operate, such as employment and investment in community assets. There is evidence of value derived from the potential of P2P, CSC and TE models to develop or build on existing social connectivity, a sense of shared purpose, and enabling participants to contribute to the environmental and social sustainability of electricity systems.

We took economic value to refer to an amount of money, goods or services. We identified evidence for two main sources of economic value. The first was savings for P2P, CSC and TE participants due to decreases in energy purchasing costs, when prosumers offer electricity at a lower price than is available in the wider market. The second was the increased revenues that P2P, CSC and TE participants can earn from selling their excess generation within the scheme compared to in the wider market. However, evidence is mixed on the extent to which these factors (compared to others, such as the sources of social value described above), affect choice to participate in P2P, CSC and TE schemes. There is the potential for other forms of economic value to be realized, such as through demand shifting to times of lower energy price, demand reductions, and payment for provision of flexibility services, but these have been deployed only to a limited extent to date.

The different types of user value identified in this study highlight the differences between the three models regarding their potential to deliver specific types of value. The majority of papers identified and reviewed in this study are about P2P energy trading models, and it is important to note that the conceptual delineation between P2P, CSC and TE models remains contested in the literature. However, we found that, in general, CSC models typically exist at the smallest scale, with an emphasis on self-consumption and 
the generation of local benefit both economic and social. TE models, on the other hand, emphasize system-level interactions, including reduced costs placed on the wider energy systems and the potential for broader participation. Finally, P2P models are seen as a way to achieve energy independence, including less reliance on traditional utilities and system operators and greater decision-making autonomy on the part of households, as well as economic value through increased export prices and decreased import prices.

1. Our reading of the literature points to a number of recommendations for researchers and practitioners: First is that the literature reveals tensions and trade-offs among forms of economic and social value. These include tensions between the economic value that may be derived from these models and non-market values such as social relationships; between the interests of prosumers and those of retailers or network operators; and between BAU conditions and the potential but uncertain value that may be gained from new energy models. Thus, the (local) governments and business practitioners considering adoption of such models must account for the value that prospective participants ascribe to doing nothing (BAU) and perceived risk of action due to uncertainty of future benefits.

2. P2P, C2C and TE models should not rely solely on economic value to drive adoption and participation, as it may not be possible to arrive at compromises that are equally beneficial across different consumers, prosumers, retailers and network owners. Expanding beyond economic self-interest, by understanding and leveraging social and community values, can provide further motivating factors that broaden the perceived value of stakeholder participation while also incorporating wider community benefits.

3. However, while social values such as local benefits/provenance and strengthened social relationships are potential features of $\mathrm{P} 2 \mathrm{P}, \mathrm{CSC}$ and TE models, our findings suggest that they are not inherent in their design. This means that the social and economic value objectives of these business models and prospective actual businesses that would adopt these models) must be purposefully created by participants and made explicit during their conception. It is important to understand what works for who (i.e., values created in various relationships) and in what context (i.e., cultural, economic, institutional, power structures and political struggles), as well as the distribution of value among those participating - or not participating —in P2P, CSC and TE models. In short, while in theory a business model could be reused anywhere, we suggest that, in practice, the success of such models will be greatly dependant on their contextual adaptation to the local cultural and other realities.

Author Contributions: S.A.: conceptualization, methodology, investigation, formal analysis, writingoriginal draft, writing-review and editing, project administration; D.B.: conceptualization, investigation, writing—original draft; J.P.C.Á.: conceptualization, investigation, visualization; R.C.: conceptualization, investigation, writing—original draft, writing—review and editing; M.J.F.: conceptualization, methodology, investigation, writing—original draft; U.J.J.H.: conceptualization, investigation, writing—original draft; K.H.: conceptualization, investigation; C.J.: conceptualization, investigation, writing—original draft; L.K.: investigation, writing—original draft; M.M.: conceptualization, investigation, writing — original draft; K.S.: investigation, writing—original draft; A.S.: conceptualization, investigation, writing-original draft; N.W.: conceptualization, methodology, investigation, writing - original draft. All authors have read and agreed to the published version of the manuscript.

Funding: This publication is part of the work of the Global Observatory on Peer-to-Peer, Community Self-Consumption and Transactive Energy Models (GO-P2P), a Task of the User-Centred Energy Systems Technology Collaboration Programme (Users TCP), under the auspices of the International Energy Agency (IEA). GO-P2P benefits from the support of Australia, Belgium, Ireland, Italy, The Netherlands, Switzerland, the United Kingdom and United States. S.A. is funded by the Australian Renewable Energy Agency (ARENA) as part of ARENA's International Engagement Program. D.B. is funded by the European Commission Horizon 2020 projects: PROSumers in the Energy Union (PROSEU) grant agreement No. 764056; and grant agreement No. 814945 (SolBio-Rev). J.P.C.Á. is funded by the UK Royal Academy of Engineering through a Transforming Systems through 
Partnership 20/21 Award (TSP2021/100067). R.C. is funded through UK Research \& Innovation grants RES (EP/R007373/1) and EnergyREV (EP/S031863/1). M.J.F. is funded through UK Research and Innovation through the Centre for Research into Energy Demand Solutions, grant reference number EP/R035288/1, and UK Research and Innovation Grant No EP/S031863/1 “Energy Revolution Research Consortium-Core-EnergyREV", administered by the Engineering and Physical Sciences Research Council (EPSRC). C.J. is funded by UK Research and Innovation through CREDS (EP/R035288/1). M.M. is funded by the Flemish Government through FWO SBO project SNIPPET S007619. N.W. is funded by UK Research and Innovation through the EPSRC Centre for Doctoral Training in Energy Demand (EP/LO1517X/1).

Institutional Review Board Statement: Not applicable.

Informed Consent Statement: Not applicable.

Data Availability Statement: Not applicable.

Conflicts of Interest: The authors declare no conflict of interest.

\section{Appendix A}

Table A1. The searches that were run to identify the results included in the review.

\begin{tabular}{|c|c|c|c|c|}
\hline Database & Search String & Search Field & Number of Results & Search Date \\
\hline Scopus & $\begin{array}{l}\text { TITLE-ABS-KEY ("peer-to-peer" OR } \\
\text { "peer to peer" OR p2p OR } \\
\text { "commun* self-consump*" OR } \\
\text { transactive OR "local energy } \\
\text { market*" OR "mutual energy } \\
\text { exchange" OR “local energy trading" } \\
\text { OR “decentralised energy trading" } \\
\text { OR "distributed energy trading" OR } \\
\text { "private wire" OR minigrid*) AND } \\
\text { TITLE-ABS-KEY (energy OR } \\
\text { electricity OR power) AND } \\
\text { TITLE-ABS-KEY (societ* OR social } \\
\text { OR prosumer* OR consumer* OR } \\
\text { customer OR user OR communit* } \\
\text { OR independen* OR *sufficien* OR } \\
\text { democra* OR right* OR justice OR } \\
\text { *equit* OR *equal* OR "non-market" } \\
\text { OR econom* OR financ* OR bill* OR } \\
\text { pric* OR cost* OR income OR } \\
\text { business OR earn* OR pover* OR } \\
\text { cultur* OR common* OR return*) }\end{array}$ & $\begin{array}{c}\text { Article title, Abstract, } \\
\text { Keywords }\end{array}$ & 3214 & 3 August 2020 \\
\hline
\end{tabular}


Table A1. Cont.

\begin{tabular}{|c|c|c|c|c|}
\hline Database & Search String & Search Field & Number of Results & Search Date \\
\hline Web of Science & $\begin{array}{l}\text { AB = ("peer-to-peer" OR "peer to } \\
\text { peer" OR p2p OR "commun* } \\
\text { self-consump*" OR transactive OR } \\
\text { "sharing economy" OR } \\
\text { "collaborative consumption" OR } \\
\text { "collaborative economy" OR "peer } \\
\text { economy" OR "platform economy" } \\
\text { OR "local energy market" OR } \\
\text { "mutual energy exchange" OR } \\
\text { "decentralised energy trading" OR } \\
\text { "distributed energy trading" OR } \\
\text { "private wire" OR minigrid*) AND } \\
\text { AB = (energy OR electricity OR } \\
\text { power) AND AB = (value OR people } \\
\text { OR societ* OR social OR prosumer } \\
\text { OR consumer OR customer OR user } \\
\text { OR communit* OR independen* OR } \\
\text { sufficien* OR democra* OR right* } \\
\text { OR justice OR equit* OR equal* OR } \\
\text { "non-market" OR econom* OR } \\
\text { financ* OR bill* OR pric* OR cost* } \\
\text { OR income OR business OR earn* } \\
\text { OR pover* OR cultur* OR common* } \\
\text { OR return*) } \\
\text { Conducted the same search for TI (Title) } \\
\text { and AK (Author Keywords) } \\
\text { Combined search results from the three } \\
\text { sets as follows: (AB results) OR (TI } \\
\text { results) OR (AK results) }\end{array}$ & $\begin{array}{c}\text { Article title, Abstract, } \\
\text { Keywords }\end{array}$ & Not recorded & 3 August 2020 \\
\hline Science Direct & $\begin{array}{l}\text { (peer-to-peer OR transactive) AND } \\
\text { energy AND (people OR social OR } \\
\text { economic OR community OR value } \\
\text { OR culture }\end{array}$ & $\begin{array}{c}\text { Article title, Abstract, } \\
\text { Keywords }\end{array}$ & Not recorded & 3 August 2020 \\
\hline
\end{tabular}

(Note: Here * is used in a search string to capture words with the same root but alternative prefixes or suffixes; e.g., societ* will match such words as society, societal, etc.).

\section{References}

1. Chaurey, A.; Kandpal, T.C. Assessment and Evaluation of PV Based Decentralized Rural Electrification: An Overview. Renew. Sustain. Energy Rev. 2010, 14, 2266-2278. [CrossRef]

2. Parra, D.; Swierczynski, M.; Stroe, D.I.; Norman, S.A.; Abdon, A.; Worlitschek, J.; O’Doherty, T.; Rodrigues, L.; Gillott, M.; Zhang, X.; et al. An Interdisciplinary Review of Energy Storage for Communities: Challenges and Perspectives. Renew. Sustain. Energy Rev. 2017, 79, 730-749. [CrossRef]

3. Siano, P. Demand Response and Smart Grids-A Survey. Renew. Sustain. Energy Rev. 2014, 30, 461-478. [CrossRef]

4. Hirsch, A.; Parag, Y.; Guerrero, J. Microgrids: A Review of Technologies, Key Drivers, and Outstanding Issues. Renew. Sustain. Energy Rev. 2018, 90, 402-411. [CrossRef]

5. Engelken, M.; Römer, B.; Drescher, M.; Welpe, I.M.; Picot, A. Comparing Drivers, Barriers, and Opportunities of Business Models for Renewable Energies: A Review. Renew. Sustain. Energy Rev. 2016, 60, 795-809. [CrossRef]

6. Behrangrad, M. A Review of Demand Side Management Business Models in the Electricity Market. Renew. Sustain. Energy Rev. 2015, 47, 270-283. [CrossRef]

7. Sousa, T.; Soares, T.; Pinson, P.; Moret, F.; Baroche, T.; Sorin, E. Peer-to-Peer and Community-Based Markets: A Comprehensive Review. Renew. Sustain. Energy Rev. 2019, 104, 367-378. [CrossRef]

8. Guerrero, J.; Gebbran, D.; Mhanna, S.; Chapman, A.C.; Verbič, G. Towards a Transactive Energy System for Integration of Distributed Energy Resources: Home Energy Management, Distributed Optimal Power Flow, and Peer-to-Peer Energy Trading. Renew. Sustain. Energy Rev. 2020, 132, 110000. [CrossRef]

9. Warneryd, M.; Håkansson, M.; Karltorp, K. Unpacking the Complexity of Community Microgrids: A Review of Institutions' Roles for Development of Microgrids. Renew. Sustain. Energy Rev. 2020, 121, 109690. [CrossRef] 
10. Montakhabi, M.; van der Graaf, S.; Ballon, P.; Mustafa, M. Prosumers' Business Models in Future Electricity Markets: Peer-to-Peer, Community Self-Consumption, and Transactive Energy Models. Manuscript Submitted for Publication. Bus. Model Conf. 2021, in press.

11. Watson, N.; Gorbatcheva, A. Defining Peer to Peer, Collective Self-Consumption, and Transactive Energy Models. in preparation.

12. Schwartz, S.H. An Overview of the Schwartz Theory of Basic Values. Online Read. Psychol. Cult. 2012, 2, 2307-0919. [CrossRef]

13. Brown, D.; Hall, S.; Davis, M.E. What Is Prosumerism for? Exploring the Normative Dimensions of Decentralised Energy Transitions. Energy Res. Soc. Sci. 2020, 66, 101475. [CrossRef]

14. Laasch, O. Beyond the Purely Commercial Business Model: Organizational Value Logics and the Heterogeneity of Sustainability Business Models. Long Range Plann. 2018, 51, 158-183. [CrossRef]

15. Morstyn, T.; Farrell, N.; Darby, S.J. Using Peer-to-Peer Energy-Trading Platforms to Incentivize Prosumers to Form Federated Power Plants. Nat. Energy 2018, 3, 94-101. [CrossRef]

16. Creamer, E.; Eadson, W.; van Veelen, B.; Pinker, A.; Tingey, M.; Braunholtz-Speight, T.; Markantoni, M.; Foden, M.; Lacey-Barnacle, M. Community Energy: Entanglements of Community, State, and Private Sector. Geogr. Compass 2018, 12, 1-16. [CrossRef]

17. Roelich, K.; Bale, C.S.E.; Turner, B.; Neall, R. Institutional Pathways to Municipal Energy Companies in the UK: Realising Co-Benefits to Mitigate Climate Change in Cities. J. Clean. Prod. 2018, 182, 727-736. [CrossRef]

18. Brisbois, M.C. Powershifts: A Framework for Assessing the Growing Impact of Decentralized Ownership of Energy Transitions on Political Decision-Making. Energy Res. Soc. Sci. 2019, 50, 151-161. [CrossRef]

19. Klein, L.P.; Allegretti, G.; Hes, D.; Melkas, H. Revealing Social Values in the Context of Peer-to-Peer Energy Sharing: A Methodological Approach. Sustain. Futur. 2021, 3, 100043. [CrossRef]

20. Hall, S.; Roelich, K. Business Model Innovation in Electricity Supply Markets: The Role of Complex Value in the United Kingdom. Energy Policy 2016, 92, 286-298. [CrossRef]

21. Richter, M. Business Model Innovation for Sustainable Energy: German Utilities and Renewable Energy. Energy Policy 2013, 62, 1226-1237. [CrossRef]

22. Parag, Y.; Sovacool, B.K. Electricity Market Design for the Prosumer Era. Nat. Energy 2016, 1, 1-6. [CrossRef]

23. Brown, D.; Hall, S.; Davis, M.E. Prosumers in the Post Subsidy Era: An Exploration of New Prosumer Business Models in the UK Energy Policy 2019, 135, 110984. [CrossRef]

24. Brown, T.; Schlachtberger, D.; Kies, A.; Schramm, S.; Greiner, M. Synergies of Sector Coupling and Transmission Reinforcement in a Cost-Optimised, Highly Renewable European Energy System. Energy 2018, 160, 720-739. [CrossRef]

25. Ruggiero, S.; Onkila, T.; Kuittinen, V. Realizing the Social Acceptance of Community Renewable Energy: A Process-Outcome Analysis of Stakeholder Influence. Energy Res. Soc. Sci. 2014, 4, 53-63. [CrossRef]

26. PRISMA. PRISMA 2020 Checklist. 2020. Available online: www.prisma-statement.org (accessed on 15 November 2021).

27. Identifying the Evidence: Literature Searching and Evidence Submission. Available online: https://www.nice.org.uk/process/ pmg20/chapter/identifying-the-evidence-literature-searching-and-evidence-submission (accessed on 15 November 2021).

28. Ecker, F.; Spada, H.; Hahnel, U.J.J. Independence without Control: Autarky Outperforms Autonomy Benefits in the Adoption of Private Energy Storage Systems. Energy Policy 2018, 122, 214-228. [CrossRef]

29. Smale, R.; Kloppenburg, S. Platforms in Power: Householder Perspectives on the Social, Environmental and Economic Challenges of Energy Platforms. Sustainability 2020, 12, 692. [CrossRef]

30. Hahnel, U.J.J.; Herberz, M.; Pena-Bello, A.; Parra, D.; Brosch, T. Becoming Prosumer: Revealing Trading Preferences and Decision-Making Strategies in Peer-to-Peer Energy Communities. Energy Policy 2020, in press. [CrossRef]

31. Kirchhoff, H.; Strunz, K. Key Drivers for Successful Development of Peer-to-Peer Microgrids for Swarm Electrification. Appl. Energy 2019, 244, 46-62. [CrossRef]

32. Wörner, A.; Ableitner, L.; Meeuw, A.; Wortmann, F.; Tiefenbeck, V. Peer-to-Peer Energy Trading in the Real World: Market Design and Evaluation of the User Value Proposition. In Proceedings of the 40th International Conference on Information Systems, ICIS 2019, Munich, Germany, 15-18 December 2019.

33. Spasova, B.; Kawamoto, D.; Takefuji, Y. Evaluation of the Effects of Bidding Strategy with Customized Pricing on the Individual Prosumer in a Local Energy Market. Adv. Sci. Technol. Eng. Syst. 2019, 4, 366-379. [CrossRef]

34. Wilkins, D.J.; Chitchyan, R.; Levine, M. Peer-to-Peer Energy Markets: Understanding the Values of Collective and Community Trading. In Proceedings of the 2020 CHI Conference on Human Factors in Computing Systems, Honolulu, HI, USA, 21 April 2020; pp. 1-14.

35. Hackbarth, A.; Löbbe, S. Attitudes, Preferences, and Intentions of German Households Concerning Participation in Peer-to-Peer Electricity Trading. Energy Policy 2020, 138, 111238. [CrossRef]

36. Löbbe, S.; Hackbarth, A.; Stillahn, T.; Pfeiffer, L.; Rohbogner, G. Chapter 4-Customer Participation in P2P Trading: A German Energy Community Case Study. In Behind and Beyond the Meter; Sioshansi, F., Ed.; Academic Press: Cambridge, MA, USA, 2020; pp. 83-104, ISBN 978-0-12-819951-0.

37. Ableitner, L.; Meeuw, A.; Schopfer, S.; Tiefenbeck, V.; Wortmann, F.; Wörner, A. Quartierstrom-Implementation of a Real World Prosumer Centric Local Energy Market in Walenstadt, Switzerland. arXiv 2019, arXiv:190507242.

38. Mengelkamp, E.; Schönland, T.; Huber, J.; Weinhardt, C. The Value of Local Electricity-A Choice Experiment among German Residential Customers. Energy Policy 2019, 130, 294-303. [CrossRef] 
39. Wilkinson, S.; Hojckova, K.; Eon, C.; Morrison, G.M.; Sandén, B. Is Peer-to-Peer Electricity Trading Empowering Users? Evidence on Motivations and Roles in a Prosumer Business Model Trial in Australia. Energy Res. Soc. Sci. 2020, 66, 101500. [CrossRef]

40. Kubli, M.; Loock, M.; Wüstenhagen, R. The Flexible Prosumer: Measuring the Willingness to Co-Create Distributed Flexibility. Energy Policy 2018, 114, 540-548. [CrossRef]

41. Scuri, S.; Tasheva, G.; Barros, L.; Nunes, N.J. An HCI Perspective on Distributed Ledger Technologies for Peer-to-Peer Energy Trading. In IFIP Conference on Human-Computer Interaction; Springer: Cham, Switzerland, 2019; Volume 11748 LNCS, pp. 91-111. [CrossRef]

42. Mengelkamp, E.; Staudt, P.; Gärttner, J.; Weinhardt, C.; Huber, J. Quantifying Factors for Participation in Local Electricity Markets. In Proceedings of the 2018 15th International Conference on the European Energy Market (EEM), Lodz, Poland, 27-29 June 2018; pp. $1-5$.

43. Ableitner, L.; Tiefenbeck, V.; Meeuw, A.; Wörner, A.; Fleisch, E.; Wortmann, F. User Behavior in a Real-World Peer-to-Peer Electricity Market. Appl. Energy 2020, 270, 115061. [CrossRef]

44. Fell, M.J.; Schneiders, A.; Shipworth, D. Consumer Demand for Blockchain-Enabled Peer-to-Peer Electricity Trading in the United Kingdom: An Online Survey Experiment. Energies 2019, 12, 3913. [CrossRef]

45. Singh, A.; Strating, A.T.; Romero Herrera, N.A.; Mahato, D.; Keyson, D.V.; van Dijk, H.W. Exploring Peer-to-Peer Returns in off-Grid Renewable Energy Systems in Rural India: An Anthropological Perspective on Local Energy Sharing and Trading. Energy Res. Soc. Sci. 2018, 46, 194-213. [CrossRef]

46. Singh, A.; Strating, A.T.; Romero Herrera, N.A.; van Dijk, H.W.; Keyson, D.V. Towards an Ethnography of Electrification in Rural India: Social Relations and Values in Household Energy Exchanges. Energy Res. Soc. Sci. 2017, 30, 103-115. [CrossRef]

47. Plewnia, F.; Guenther, E. The Transition Value of Business Models for a Sustainable Energy System: The Case of Virtual Peer-to-Peer Energy Communities. Organ. Environ. 2020, 34, 479-503. [CrossRef]

48. Dukovska, I.; Paterakis, N.G.; Slootweg, H.J.G. Local Energy Exchange Considering Heterogeneous Prosumer Preferences. In Proceedings of the 2018 International Conference on Smart Energy Systems and Technologies (SEST), Seville, Spain, 10-12 September 2018; IEEE: Piscataway, NJ, USA, 2018.

49. Klein, L.P.; Krivoglazova, A.; Matos, L.; Landeck, J.; De Azevedo, M. A Novel Peer-to-peer Energy Sharing Business Model for the Portuguese Energy Market. Energies 2019, 13, 125. [CrossRef]

50. Müller, S.C.; Welpe, I.M. Sharing Electricity Storage at the Community Level: An Empirical Analysis of Potential Business Models and Barriers. Energy Policy 2018, 118, 492-503. [CrossRef]

51. Mengelkamp, E.; Gärttner, J.; Rock, K.; Kessler, S.; Orsini, L.; Weinhardt, C. Designing Microgrid Energy Markets. Appl. Energy 2018, 210, 870-880. [CrossRef]

52. Pumphrey, K.; Walker, S.L.; Andoni, M.; Robu, V. Green Hope or Red Herring? Examining Consumer Perceptions of Peer-to-Peer Energy Trading in the United Kingdom. Energy Res. Soc. Sci. 2020, 68, 101603. [CrossRef]

53. Klein, L.P.; Matos, L.M.; Allegretti, G. A Pragmatic Approach towards End-User Engagement in the Context of Peer-to-Peer Energy Sharing. Energy 2020, 205, 118001. [CrossRef]

54. Laursen, L. Grids of All Sizes: Solar Minigrids in Bangladesh Are Changing the Lives of People in Remote Rural Areas. Nature 2017, 551, S148-S149. [CrossRef]

55. Shrestha, A.; Bishwokarma, R.; Chapagain, A.; Banjara, S.; Aryal, S.; Mali, B.; Thapa, R.; Bista, D.; Hayes, B.P.; Papadakis, A.; et al Peer-to-Peer Energy Trading in Micro/Mini-Grids for Local Energy Communities: A Review and Case Study of Nepal. IEEE Access 2019, 7, 131911-131928. [CrossRef]

56. Wang, N.N. Transactive Control for Connected Homes and Neighbourhoods. Nat. Energy 2018, 3, 907-909. [CrossRef]

57. Ahl, A.; Yarime, M.; Tanaka, K.; Sagawa, D. Review of Blockchain-Based Distributed Energy: Implications for Institutional Development. Renew. Sustain. Energy Rev. 2019, 107, 200-211. [CrossRef]

58. Binus, J. Planning for Change in the Electric Power Industry: A Primer for Transactive Energy Scenario Development. In Proceedings of the PICMET 2019, Portland, OR, USA, 25-29 August 2019; IEEE: Piscataway, NJ, USA; 2019.

59. Brilliantova, V.; Thurner, T.W. Blockchain and the Future of Energy. Technol. Soc. 2019, 57, 38-45. [CrossRef]

60. Filipovic, S.; Radovanovic, M.; Lior, N. What Does the Sharing Economy Mean for Electric Market Transitions? A Review with Sustainability Perspectives. Energy Res. Soc. Sci. 2019, 58, 101258. [CrossRef]

61. SunContract. Available online: https://suncontract.org/self-sufficient/ (accessed on 15 November 2021).

62. Powerpeers. Available online: https://www.powerpeers.nl/ (accessed on 15 November 2021).

63. Fell, M.J. Anticipating Distributional Impacts of Peer-to-Peer Energy Trading: Inference from a Realist Review of Evidence on Airbnb. Clean. Responsible Consum. 2021, 2, 100013. [CrossRef]

64. Singh, A. Conceptualizing Inter-Household Energy Exchanges: An Anthropology-through-Design Approach. Ph.D. Thesis, Delft University of Technology, Delft, The Netherlands, 2019. Available online: https://repository.tudelft.nl/islandora/object/uuid\% 3A57be7165-2726-4a1a-b076-c5ed3988e00b (accessed on 15 November 2021).

65. Müller, M.O.; Stämpfli, A.; Dold, U.; Hammer, T. Energy Autarky: A Conceptual Framework for Sustainable Regional Development. Energy Policy 2011, 39, 5800-5810. [CrossRef]

66. Langley, P.; Leyshon, A. Platform Capitalism: The Intermediation and Capitalization of Digital Economic Circulation. Finance Soc. 2017, 3, 11-31. [CrossRef] 
67. Kloppenburg, S.; Boekelo, M. Digital Platforms and the Future of Energy Provisioning: Promises and Perils for the next Phase of the Energy Transition. Energy Res. Soc. Sci. 2019, 49, 68-73. [CrossRef]

68. Jenkins, K.; Sovacool, B.K.; McCauley, D. Humanizing Sociotechnical Transitions through Energy Justice: An Ethical Framework for Global Transformative Change. Energy Policy 2018, 117, 66-74. [CrossRef]

69. Hiteva, R.; Sovacool, B. Harnessing Social Innovation for Energy Justice: A Business Model Perspective. Energy Policy 2017, 107, 631-639. [CrossRef]

70. Sovacool, B.K. What Are We Doing Here? Analyzing Fifteen Years of Energy Scholarship and Proposing a Social Science Research Agenda. Energy Res. Soc. Sci. 2014, 1, 1-29. [CrossRef]

71. Montakhabi, M.; van der Graaf, S.; Ballon, P.; Walravens, N.; Vanhaverbeke, W. Defining the Business Ecosystem of Peer-toPeer Electricity Trading. In Proceedings of the 6th International Conference on New Business Models, Halmstad, Sweden, 9-11 June 2021; Halmstad University Press: Halmstad, Sweden, 2021; pp. 163-188. 